Research Article

\title{
Sensorless Control of Brushless Doubly Fed Induction Generator with Nonlinear Loads for Stand-Alone Power Generation Systems
}

\author{
Wantai Liu $\mathbb{D}^{1}{ }^{1}$ Weicai Xie, ${ }^{2}$ Yunong Lv, ${ }^{1}$ and Zhan Zhou ${ }^{1}$ \\ ${ }^{1}$ Hunan Electrical College of Technology, Xiangtan 411101, China \\ ${ }^{2}$ Hunan Institute of Engineering, Xiangtan 411101, China
}

Correspondence should be addressed to Wantai Liu; 50488727@qq.com

Received 5 February 2020; Revised 20 May 2020; Accepted 1 June 2020; Published 11 July 2020

Guest Editor: Yi Qi

Copyright (c) 2020 Wantai Liu et al. This is an open access article distributed under the Creative Commons Attribution License, which permits unrestricted use, distribution, and reproduction in any medium, provided the original work is properly cited.

\begin{abstract}
This paper presents a sensorless control scheme for the stand-alone brushless doubly fed induction generator (BDFIG) feeding nonlinear loads. The fundamental and harmonic components of the distorted power winding (PW) voltage caused by the nonlinear loads are extracted and controlled separately. A rotor speed observer is employed to estimate the speed based on the PW voltage and control winding $(\mathrm{CW})$ current without the need of any other machine parameters except for the number of pole pairs. Since the $d$ - and $q$-axis references of the CW current from the PW voltage control loop contain both dc and ac components, which cannot be tracked easily by conventional PI controllers, a CW predictive current controller is designed to regulate the CW current. Finally, the performance of the proposed control scheme is verified by comprehensive experiments on a 35-kVA prototype BDFIG.
\end{abstract}

\section{Introduction}

The brushless doubly fed induction generator (BDFIG) contains two stator windings with different pole pairs, one of which is called power winding (PW) and the other one called control winding $(\mathrm{CW})$ [1]. A specially designed rotor allows an indirect coupling between the two stator windings [2]. A stand-alone BDFIG can generate voltage with constant amplitude and frequency by employing a fractionally rated power converter while the rotor speed and load are changing, which are suitable for variable speed constant frequency (VSCF) power generation systems [3]. As shown in Figure 1, the stand-alone BDFIG control system includes both the CW side converter (CSC) supplying the $\mathrm{CW}$ with frequency-variable exciting current and the load side converter (LSC) connected between the $\mathrm{dc}$ bus and the loads for regulating the dc bus voltage and achieving bidirectional energy flow. Generally, the electrical loads include both linear loads (such as air conditioners and lighting equipment) and nonlinear loads (typically the front rectifier of converters driving fans, pumps, winders, and so on).

However, a nonlinear load would result in a distorted PW three-phase current, which could produce harmonic voltage drops across the three-phase impedances of the PW, resulting in a distorted $\mathrm{PW}$ voltage. In order to make the BDFIG power generation system to generate a voltage, which has constant amplitude and frequency with as few harmonics as possible under the nonlinear load condition, it is necessary to propose an effective and enhanced control strategy. In addition, the control of the CSC needs the information of the rotor position and speed. However, the conventional control strategies obtain the rotor position and speed by employing the corresponding sensors, which would increase the cost and decrease the reliability of the system. So, it is necessary to eliminate the rotor position and speed sensors.

The vector control schemes of BDFIGs for grid-connected wind power generation have been developed under balanced operation $[4]$, unbalanced operation $[5,6]$, and 
low-voltage ride through [7]. However, all control schemes proposed in [4-7] employ the rotor position/speed sensor to acquire the rotor position/speed. Some other papers, such as $[8,9]$, have discussed the rotor speed observers for the grid-connected brushless doubly fed reluctance generator (BDFRG) similar to the grid-connected BDFIG. It is noted that these rotor speed observers proposed in $[8,9]$ both need specific parameters of the PW inductance and resistance to estimate the flux. However, in the stand-alone BDFIG system, nonlinear loads are frequently connected to the system, leading to distorted PW voltage and current. Therefore, it is difficult to accurately estimate the PW flux, and consequently the observed rotor speed is inaccurate. Moreover, the dependence on the machine parameters can also reduce the robustness of the observer.

Generally, a grid-connected wind power generation system needs to control the active and reactive power, whereas in a stand-alone power generation system, the amplitude and frequency of the output voltage should be stabilized when the rotor speed or load varies. Therefore, the control scheme of a stand-alone BDFIG is different from that of a grid-connected BDFIG. For the stand-alone BDFIG, a control scheme based on the $\mathrm{CW}$ current orientation has been designed without considering nonlinear load conditions [10]. Besides, a direct voltage control scheme has been developed under linear load conditions [11]. The transient control of reactive current for the LSC in the stand-alone BDFIG power generation system has been proposed in [12] to improve the quality of the output voltage. Some studies have investigated the control scheme of the stand-alone doubly fed induction generator (DFIG) under nonlinear load conditions [13-15]; there are few related studies on BDFIG. A harmonic voltage and current elimination method for stand-alone BDFIG with nonlinear loads has been proposed in [16]. However, this method is achieved by using a speed sensor.

This paper presents an enhanced sensorless control scheme of the stand-alone BDFIG under nonlinear load conditions. The fundamental and harmonic components of the PW voltage are extracted and then regulated separately. A new rotor speed observer is designed to observe the rotor position and speed based on the PW voltage and CW current. Since the $d$ - and $q$-axis references of the $\mathrm{CW}$ current from the PW voltage control loop contain both dc and ac components, the predictive control method is introduced to regulate the $\mathrm{CW}$ current. Comprehensive experimental results on a $35-\mathrm{kVA}$ prototype BDFIG are presented to validate the effectiveness of the proposed control scheme.

The following sections of this paper is organized as follows: firstly, the operational principle and dynamic model of BDFIG are introduced in Section 2; the system analysis and modeling under nonlinear loads is presented in Section 3; the control scheme is proposed in Section 4; experimental results are illustrated in Section 5; and finally the conclusions are drawn in Section 6.

\section{Operational Principle and Dynamic Model of BDFIG}

2.1. Basic Operational Principle of BDFIG. The BDFIG rotor mechanical angular frequency can be determined by the PW and CW angular frequencies as follows:

$$
\omega_{\mathrm{r}}=\frac{\left(\omega_{\mathrm{p}}+\omega_{\mathrm{c}}\right)}{\left(p_{\mathrm{p}}+p_{\mathrm{c}}\right)},
$$

where $p_{\mathrm{p}}$ and $p_{\mathrm{c}}$ are the numbers of pole pairs of $\mathrm{PW}$ and $\mathrm{CW}, \omega$ is the angular frequency, and the subscripts $p, c$, and $r$ indicate the $\mathrm{PW}, \mathrm{CW}$, and rotor, respectively.

In order to keep $\omega_{\mathrm{p}}$ constant, $\omega_{\mathrm{c}}$ should be changed with the variation of the rotor speed according to the following expression derived from (1):

$$
\omega_{\mathrm{c}}=\omega_{\mathrm{r}}\left(p_{\mathrm{p}}+p_{\mathrm{c}}\right)-\omega_{\mathrm{p}} .
$$

2.2. Dynamic Vector Model of BDFIG. The unified reference frame vector model proposed in [17] is employed in this paper. In the fundamental reference frame $\left(\mathrm{d} q^{+1}\right)$ rotating at the speed of $\omega_{\mathrm{p}}$, this model can be expressed as

$$
\left\{\begin{array}{l}
\mathrm{u}_{\mathrm{pdq}}^{+1}=R_{\mathrm{p}} \mathbf{i}_{\mathrm{pdq}}^{+1}+s \psi_{\mathrm{pdq}}^{+1}+j \omega_{\mathrm{p}} \psi_{\mathrm{pdq}}^{+1}, \\
\boldsymbol{\psi}_{\mathrm{pdq}}^{+1}=L_{\mathrm{p}} \mathbf{i}_{\mathrm{pdq}}^{+1}+L_{\mathrm{pr}} i_{\mathrm{rdq}}^{+1} \\
\mathbf{u}_{\mathrm{cdq}}^{+1}=R_{\mathrm{c}} \mathbf{i}_{\mathrm{cdq}}^{+1}+s \psi_{\mathrm{cdq}}^{+1}+j\left[\omega_{\mathrm{p}}-\left(p_{\mathrm{p}}+p_{\mathrm{c}}\right) \omega_{\mathrm{r}}\right] \psi_{\mathrm{cdq}}^{+1}, \\
\psi_{\mathrm{cdq}}^{+1}=L_{\mathrm{c}} \mathbf{i}_{\mathrm{cdq}}^{+1}+L_{\mathrm{cr}} \mathbf{i}_{\mathrm{rdq}}^{+1} \\
\mathbf{u}_{\mathrm{rdq}}^{+1}=R_{r} \mathbf{i}_{\mathrm{rdq}}^{+1}+s \psi_{\mathrm{rdq}}^{+1}+j\left(\omega_{\mathrm{p}}-p_{\mathrm{p}} \omega_{\mathrm{r}}\right) \psi_{\mathrm{rdq}}^{+1}, \\
\psi_{\mathrm{rdq}}^{+1}=L_{\mathrm{r}} \mathbf{i}_{\mathrm{rdq}}^{+1}+L_{\mathrm{pr}} \mathbf{i}_{\mathrm{pdq}}^{+1}+L_{\mathrm{cr}} \mathbf{i}_{\mathrm{cdq}}^{+1}
\end{array}\right.
$$

where $\mathbf{u}_{\mathrm{dq}}, \mathbf{i}_{\mathrm{dq}}$, and $\psi_{\mathrm{dq}}$ represent the voltage, current, and flux vectors, $R_{\mathrm{p}}, R_{\mathrm{c}}$, and $R_{\mathrm{r}}$ the resistances of $\mathrm{PW}, \mathrm{CW}$, and rotor, $L_{\mathrm{p}}, L_{\mathrm{c}}$, and $L_{\mathrm{r}}$ the self-inductances of PW, CW, and rotor, $L_{\mathrm{cr}}$ and $L_{\mathrm{cr}}$ the coupling inductances between the stator and rotor windings, respectively, $s$ the differential operator $d / \mathrm{d} t$, and superscripts +1 the fundamental reference frame.

\section{System Analysis and Modelling}

3.1. System Analysis. Nonlinear loads make the PW current distorted, which in turn causes abundant harmonic current in the CW due to the indirect coupling between the two stator windings through the rotor. And then, the PW harmonic current results in harmonic-voltage drop on the three-phase internal impedances of the PW.

Therefore, under nonlinear load conditions, the PW terminal voltage of the stand-alone BDFIG would contain significant harmonic components and consequently degrade the performance of other linear loads connected to the system. Among these harmonic components, the fifth and seventh harmonic components are the most significant ones. Figure 2 presents the impact of the nonlinear loads on the stand-alone BDFIG system. 


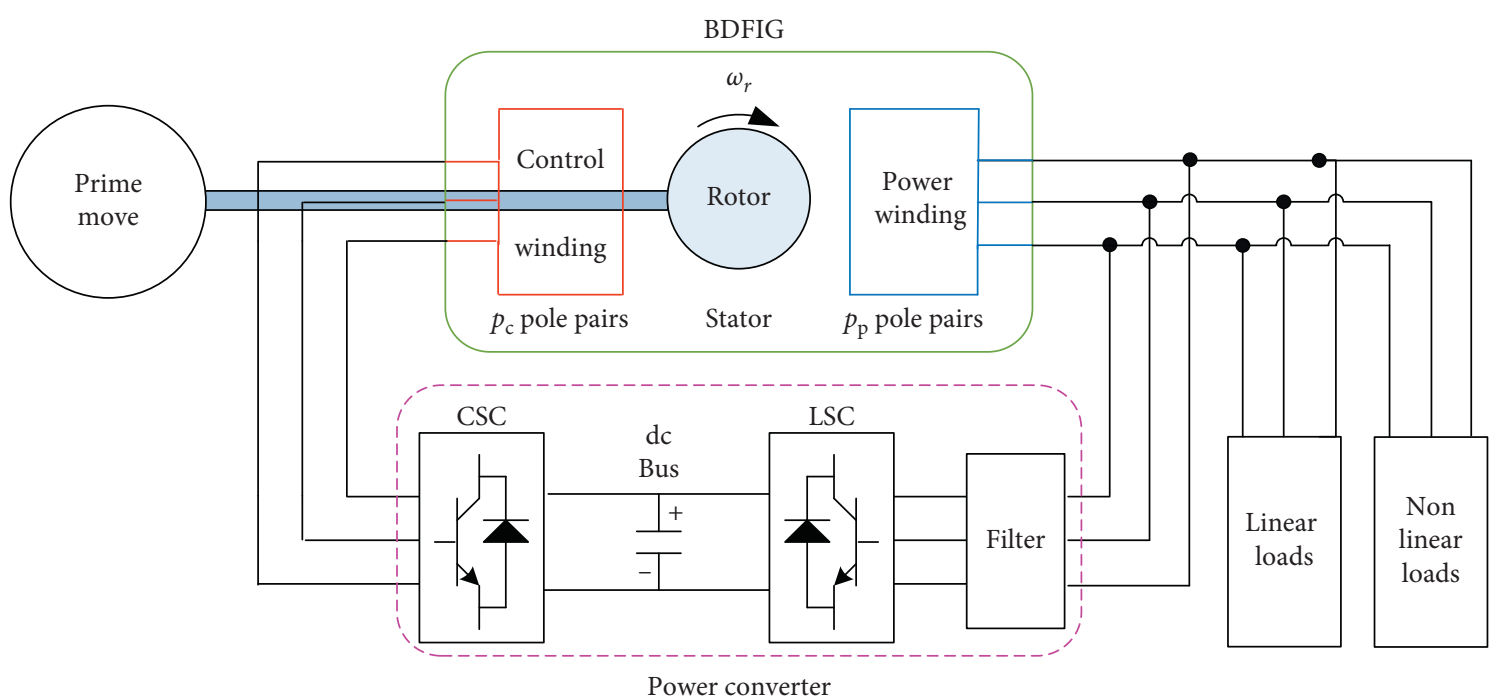

Figure 1: Configuration of the BDFIG-based stand-alone power generation system.

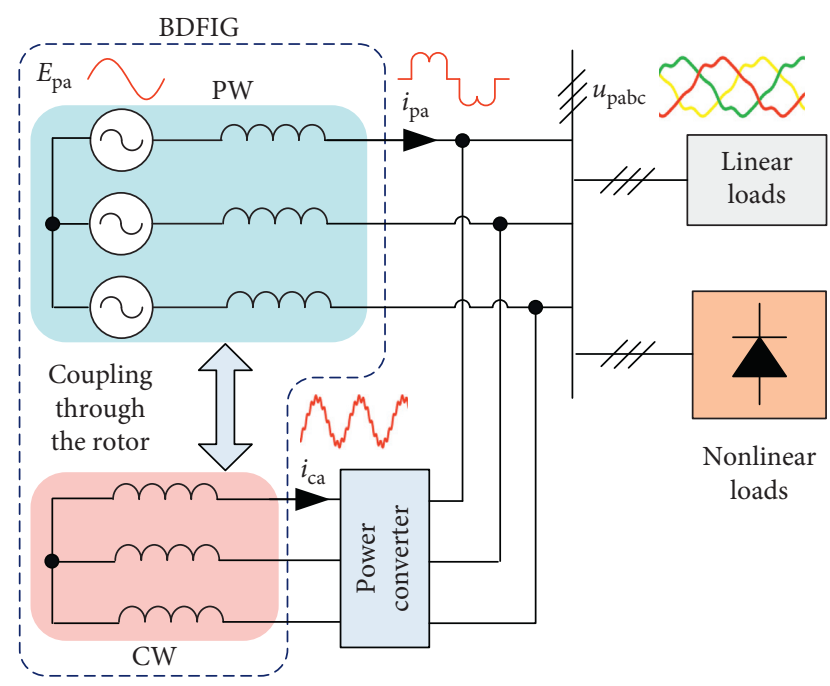

FIGURE 2: Impact of the nonlinear loads on the stand-alone BDFIG.

3.2. Mathematical Modelling. In order to derive the dynamic vector model of the stand-alone BDFIG under nonlinear loads, the other two reference frames need to be defined as shown in Figure 3. The negative fifth harmonic reference frame $\left(\mathrm{dq}^{-5}\right)$ rotates at the angular speed of $-5 \omega_{\mathrm{p}}$, and the positive seventh harmonic reference frame $\left(\mathrm{dq}^{+7}\right)$ at the angular speed of $7 \omega_{\mathrm{p}}$.

The relationship among the expressions of an arbitrary vector $\mathbf{F}_{\mathrm{dq}}$ in different reference frames can be presented as

$$
\begin{aligned}
& \mathbf{F}_{\mathrm{dq}}^{+1}=\mathbf{F}_{\mathrm{dq}}^{-5} e^{-j 6 \omega_{\mathrm{p}} t}, \\
& \mathbf{F}_{\mathrm{dq}}^{+1}=\mathbf{F}_{\mathrm{dq}}^{+7} e^{j 6 \omega_{\mathrm{p}} t},
\end{aligned}
$$

where the superscripts $+1,-5$, and +7 represent the fundamental, the negative fifth harmonic, and the positive seventh harmonic reference frames, respectively.

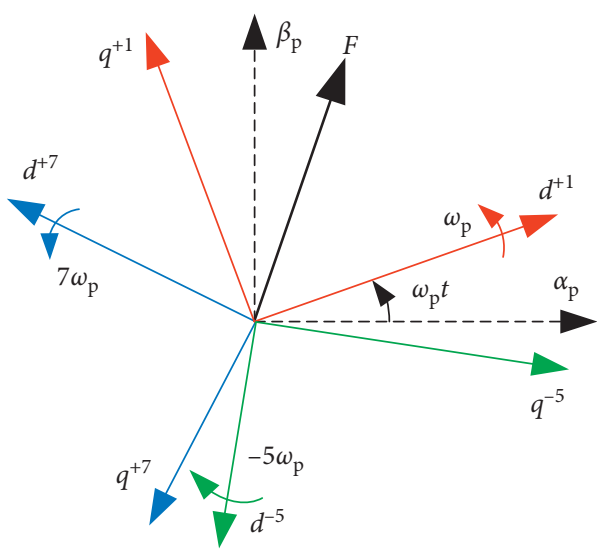

FIgURE 3: The fundamental and harmonic reference frames in the dynamic vector model of the stand-alone BDFIG under nonlinear loads.

Under nonlinear loads, the general electrical vector $\mathbf{F}_{\mathrm{dq}}^{+1}$ of a BDFIG in the reference frame $\mathrm{dq}^{+1}$ can be expressed as

$$
\mathbf{F}_{\mathrm{dq}}^{+1}=\mathbf{F}_{\mathrm{dq} 1}^{+1}+\mathbf{F}_{\mathrm{dq} 5}^{+1}+\mathbf{F}_{\mathrm{dq} 7}^{+1} \text {, }
$$

where the subscripts 1,5 , and 7 indicate the fundamental, the fifth harmonic, and the seventh harmonic components, respectively.

Substituting (4) and (5) into (6), the following can be obtained:

$$
\mathbf{F}_{\mathrm{dq}}^{+1}=\mathbf{F}_{\mathrm{dq} 1}^{+1}+\mathbf{F}_{\mathrm{dq} 5}^{-5} e^{-j 6 \omega_{\mathrm{p}} t}+\mathbf{F}_{\mathrm{dq} 7}^{+7} e^{j 6 \omega_{\mathrm{p}} t} .
$$

From (7), the voltage, current, and flux vectors of the PW in the fundamental reference frame can be expressed as

$$
\begin{aligned}
& \mathbf{u}_{\mathrm{pdq}}^{+1}=\mathbf{u}_{\mathrm{pdq} 1}^{+1}+\mathbf{u}_{\mathrm{pdq} 5}^{-5} e^{-j 6 \omega_{\mathrm{p}} t}+\mathbf{u}_{\mathrm{pdq} 7}^{+7} e^{j 6 \omega_{\mathrm{p}} t}, \\
& \mathbf{i}_{\mathrm{pdq}}^{+1}=\mathbf{i}_{\mathrm{pdq} 1}^{+1}+\mathbf{i}_{\mathrm{pdq} 5}^{-5} e^{-j 6 \omega_{\mathrm{p}} t}+\mathbf{i}_{\mathrm{pdq} 7}^{+7} e^{j 6 \omega_{\mathrm{p}} t},
\end{aligned}
$$




$$
\psi_{\mathrm{pdq}}^{+1}=\psi_{\mathrm{pdq} 1}^{+1}+\psi_{\mathrm{pdq} 5}^{-5} e^{-j 6 \omega_{\mathrm{p}} t}+\psi_{\mathrm{pdq} 7}^{+7} e^{j 6 \omega_{\mathrm{p}} t}
$$

By substituting (8)-(10) into the first part of (3), the PW fundamental- and harmonic-voltage equations in the corresponding reference frames can be derived as

$$
\begin{aligned}
& \mathbf{u}_{\mathrm{pdq} 1}^{+1}=R_{\mathrm{p}} \mathbf{i}_{\mathrm{pdq} 1}^{+1}+s \psi_{\mathrm{pdq} 1}^{+1}+j \omega_{\mathrm{p}} \psi_{\mathrm{pdq} 1}^{+1}, \\
& \mathbf{u}_{\mathrm{pdq} 5}^{-5}=R_{\mathrm{p}} \mathbf{i}_{\mathrm{pdq} 5}^{-5}+s \psi_{\mathrm{pdq} 5}^{-5}+j\left(-5 \omega_{\mathrm{p}}\right) \psi_{\mathrm{pdq} 5}^{-5}, \\
& \mathbf{u}_{\mathrm{pdq} 7}^{+7}=R_{\mathrm{p}} \mathbf{i}_{\mathrm{pdq} 7}^{+7}+s \psi_{\mathrm{pdq} 7}^{+7}+j 7 \omega_{\mathrm{p}} \psi_{\mathrm{pdq} 7}^{+7},
\end{aligned}
$$

Similarly, the PW fundamental- and harmonic-flux equations can be obtained by

$$
\begin{aligned}
& \psi_{\text {pdq1 }}^{+1}=L_{\mathrm{p}} \mathbf{i}_{\text {pdq1 }}^{+1}+L_{\text {pri }} \mathbf{i}_{\text {rdq1 } 1}^{+1}, \\
& \psi_{\text {pdq } 5}^{-5}=L_{\text {p }} \mathbf{i}_{\text {pdq } 5}^{-5}+L_{\text {pr }} \mathbf{i}_{\text {rdq5 }}^{-5}, \\
& \psi_{\text {pdq } 7}^{+7}=L_{\mathrm{p}} \mathbf{i}_{\text {pdq7 }}^{+7}+L_{\text {pr }} \mathbf{i}_{\text {rdq } 7}^{+7}
\end{aligned}
$$

A similar method can also be employed to derive the fundamental- and harmonic-voltage and flux equations of the $\mathrm{CW}$ and rotor. And then, by ignoring those harmonics with the order more than seventh, the dynamic vector model of the BDFIG under nonlinear loads can be decomposed into three sets of equations as follows:

$$
\left\{\begin{array}{l}
\mathbf{u}_{\mathrm{pdq} 1}^{+1}=R_{\mathrm{p}} \mathbf{i}_{\mathrm{pdq} 1}^{+1}+s \psi_{\mathrm{pdq} 1}^{+1}+j \omega_{\mathrm{p}} \boldsymbol{\psi}_{\mathrm{pdq} 1}^{+1} \\
\boldsymbol{\psi}_{\mathrm{pdq} 1}^{+1}=L_{\mathrm{p}} \mathbf{i}_{\mathrm{pdq} 1}^{+1}+L_{\mathrm{pr}} \mathbf{i}_{\mathrm{rdq} 1}^{+1} \\
\mathbf{u}_{\mathrm{cdq} 1}^{+1}=R_{\mathrm{c}} \mathbf{i}_{\mathrm{cdq} 1}^{+1}+s \boldsymbol{\psi}_{\mathrm{cdq} 1}^{+1}+j\left[\omega_{\mathrm{p}}-\left(p_{p}+p_{c}\right) \omega_{\mathrm{r}}\right] \boldsymbol{\psi}_{\mathrm{cdq} 1}^{+1} \\
\boldsymbol{\psi}_{\mathrm{cdq} 1}^{+1}=L_{\mathrm{c}} \mathbf{i}_{\mathrm{cdq} 1}^{+1}+L_{\mathrm{cr}} \mathbf{i}_{\mathrm{rdq} 1}^{+1} \\
\mathbf{u}_{\mathrm{rdq} 1}^{+1}=R_{\mathrm{r}} \mathbf{i}_{\mathrm{rdq} 1}^{+1}+s \boldsymbol{\psi}_{\mathrm{rdq} 1}^{+1}+j\left(\omega_{\mathrm{p}}-p_{\mathrm{p}} \omega_{\mathrm{r}}\right) \boldsymbol{\psi}_{\mathrm{rdq} 1}^{+1} \\
\boldsymbol{\psi}_{\mathrm{rdq} 1}^{+1}=L_{\mathrm{r}} \mathbf{i}_{\mathrm{rdq} 1}^{+1}+L_{\mathrm{pr}} \mathbf{i}_{\mathrm{pdq} 1}^{+1}+L_{\mathrm{cr}} \mathbf{i}_{\mathrm{cdq} 1}^{+1}
\end{array}\right.
$$

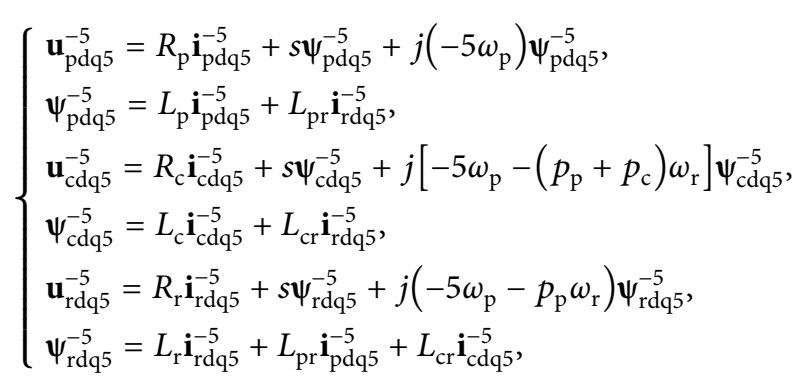

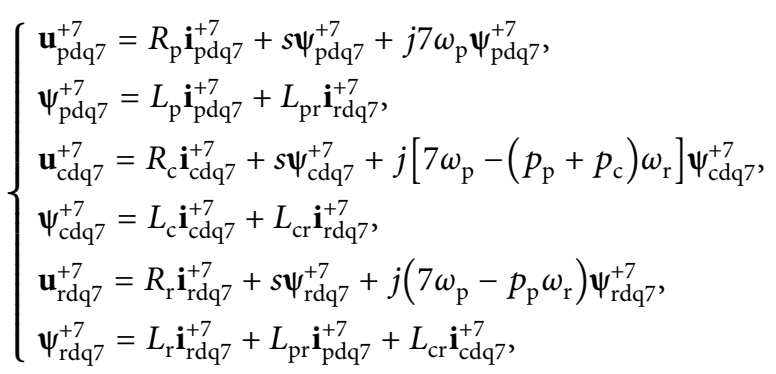

where (17)-(19) are the fundamental, fifth harmonic, and seventh harmonic equations, respectively.

\section{Design of Control Scheme}

The overall control scheme for the enhanced sensorless control of the stand-alone BDFIG with nonlinear loads is shown in Figure 4. The PW fundamental-voltage controller, based on the PW fundamental-voltage vector orientation, is employed to regulate the amplitude and frequency of the PW fundamental voltage. The PW harmonic-voltage controller can eliminate the fifth and seventh harmonic components of the PW voltage. Then, it summarizes the outputs of both PW fundamental- and harmonic-voltage controllers in order to get the references of the $\mathrm{CW} d$ - and $q$-component currents. By theoretical analysis, it is known that the references of $C W$ $d$ - and $q$-component currents contain both dc and ac parts, which cannot be tracked easily by conventional PI controllers. Therefore, a predictive current controller is employed to regulate the CW current. In addition, the multiple second-order generalized integrator-based PLL (MSOGI-PLL) [18] is used to extract the $\alpha$ - and $\beta$-components of the fundamental, fifth, and seventh harmonics of the PW voltage. The improved rotor speed observer can estimate the rotor position and speed of the BDFIG based on the PW voltage and CW current.

4.1. Control of PW Fundamental Voltage. The PW fundamental-voltage controller is based on the PW fundamental voltage vector orientation and can be derived from (17). By splitting the first part of (17) into $d$ - and $q$-components, the PW fundamental voltage in the reference frame $\mathrm{dq}^{+1}, u_{\mathrm{pd} 1}^{+1}$ and $u_{\text {pql }}^{+1}$, can be obtained by

$$
\begin{aligned}
& \mathbf{u}_{\mathrm{pd} 1}^{+1}=R_{\mathrm{p}} \mathbf{i}_{\mathrm{pd} 1}^{+1}+s \psi_{\mathrm{pd} 1}^{+1}-\omega_{\mathrm{p}} \psi_{\mathrm{pq} 1}^{+1}, \\
& \mathbf{u}_{\mathrm{pq} 1}^{+1}=R_{\mathrm{p}} \mathbf{i}_{\mathrm{pq} 1}^{+1}+s \psi_{\mathrm{pq} 1}^{+1}+\omega_{\mathrm{p}} \psi_{\mathrm{pd} 1}^{+1} .
\end{aligned}
$$

Generally, the sampling period of the power converters for BDFIG is smaller than $1 \mathrm{~ms}$, which results in the PW flux 


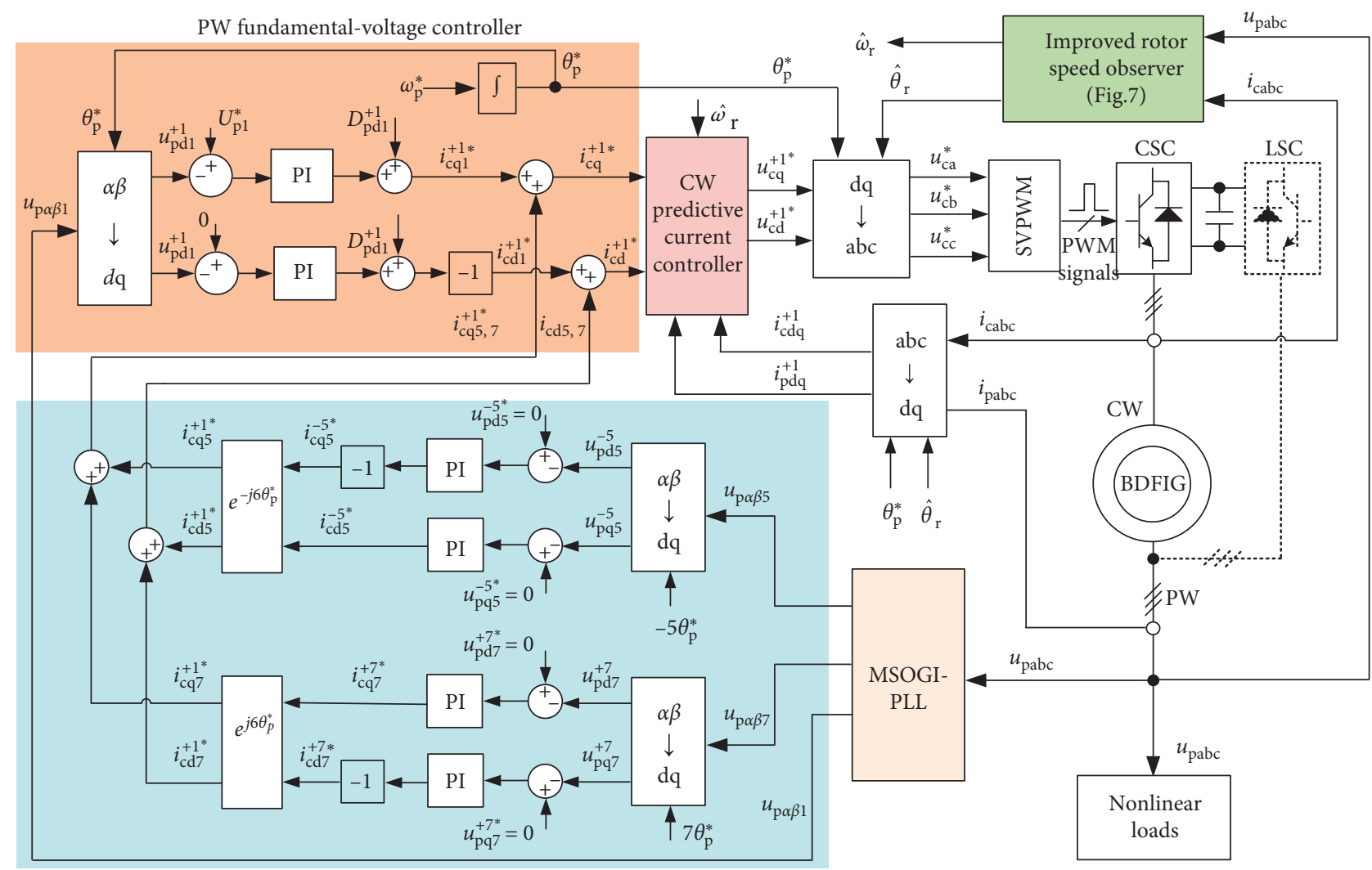

PW harmonic-voltage controller

FIgURE 4: The overall control scheme for the enhanced sensorless control of the stand-alone BDFIG with nonlinear loads.

being regarded as a constant during one sampling period. Hence, the differential terms of the flux linkages in (20) and (21) are approximately equal to 0 , and equations (20) and (21) can be simplified as

$$
\begin{aligned}
& \mathbf{u}_{\mathrm{pd} 1}^{+1}=R_{\mathrm{p}} \mathbf{i}_{\mathrm{pd} 1}^{+1}-\omega_{\mathrm{p}} \boldsymbol{\psi}_{\mathrm{pq} 1}^{+1}, \\
& \mathbf{u}_{\mathrm{pq} 1}^{+1}=R_{\mathrm{p}} \mathbf{i}_{\mathrm{pq} 1}^{+1}+\omega_{\mathrm{p}} \boldsymbol{\psi}_{\mathrm{pd} 1}^{+1} .
\end{aligned}
$$

Besides, the PW resistance $R_{\mathrm{p}}$ is usually very small, resulting in the first term on the right side of (22) and (23) being much smaller than the second term. Hence, the first term on the right side of (22) and (23) can be neglected. Consequently, equations (22) and (23) can be simplified as

$$
\begin{aligned}
& \mathbf{u}_{\mathrm{pd} 1}^{+1} \approx-\omega_{\mathrm{p}} \psi_{\mathrm{pq} 1}^{+1}, \\
& \mathbf{u}_{\mathrm{pq} 1}^{+1} \approx \omega_{\mathrm{p}} \psi_{\mathrm{pd} 1}^{+1} .
\end{aligned}
$$

Converting the second part of (17) into the form of $d$ and $q$-components, the following can be obtained:

$$
\begin{aligned}
& \psi_{\mathrm{pd} 1}^{+1}=L_{\mathrm{p}} \mathbf{i}_{\mathrm{pd} 1}^{+1}+L_{\mathrm{pp}} \mathbf{i}_{\mathrm{rd} 1}^{+1}, \\
& \psi_{\mathrm{pq} 1}^{+1}=L_{\mathrm{p}} \mathbf{i}_{\mathrm{pq} 1}^{+1}+L_{\mathrm{pr}} \mathbf{i}_{\mathrm{rq} 1}^{+1} .
\end{aligned}
$$

From the fifth and sixth parts of (17), with the rotor voltage equivalent to zero, the $d$ - and $q$-components of the rotor current can be derived as

$$
\begin{aligned}
& \mathbf{i}_{\mathrm{rd} 1}^{+1}=-\alpha_{1}^{+1} \mathbf{i}_{\mathrm{cd} 1}^{+1}+\alpha_{2}^{+1} \mathbf{i}_{\mathrm{cq} 1}^{+1}+\alpha_{3}^{+1} \mathbf{i}_{\mathrm{pd} 1}^{+1}+\alpha_{4}^{+1} \mathbf{i}_{\mathrm{pq} 1}^{+1}, \\
& \mathbf{i}_{r q 1}^{+1}=-\beta_{1}^{+1} \mathbf{i}_{\mathrm{cq} 1}^{+1}+\beta_{2}^{+1} \mathbf{i}_{\mathrm{cd} 1}^{+1}+\beta_{3}^{+1} \mathbf{i}_{\mathrm{pq} 1}^{+1}+\beta_{4}^{+1} \mathbf{i}_{\mathrm{pd} 1}^{+1} .
\end{aligned}
$$

The detailed expressions for $\alpha_{1}^{+1} \sim \alpha_{4}^{+1}$, and $\beta_{1}^{+1} \sim \beta_{4}^{+1}$ can be seen in Appendix.

Substituting (28) into (26) and substituting (29) into (27), the PW fundamental flux can be derived as

$$
\psi_{\mathrm{pd} 1}^{+1}=-L_{\mathrm{pr}} \alpha_{1}^{+1} \mathbf{i}_{\mathrm{cd} 1}^{+1}+L_{\mathrm{pr}} \alpha_{2}^{+1} \mathbf{i}_{\mathrm{cq} 1}^{+1}+\left(L_{\mathrm{p}}+L_{\mathrm{pr}} \alpha_{3}^{+1}\right) \mathbf{i}_{\mathrm{pd} 1}^{+1}+L_{\mathrm{pr}} \alpha_{4}^{+1} \mathbf{i}_{\mathrm{pq} 1}^{+1}
$$

$$
\begin{aligned}
\psi_{\mathrm{pq} 1}^{+1}= & -L_{\mathrm{pr}} \beta_{1}^{+1} \mathbf{i}_{\mathrm{cq} 1}^{+1}+L_{\mathrm{pr}} \beta_{2}^{+1} \mathbf{i}_{\mathrm{cd} 1}^{+1}+\left(L_{\mathrm{p}}+L_{\mathrm{pr}} \beta_{3}^{+1}\right) \mathbf{i}_{\mathrm{pq} 1}^{+1} \\
& +L_{\mathrm{pr}} \beta_{4}^{+1} \mathbf{i}_{\mathrm{pd} 1}^{+1} .
\end{aligned}
$$

By substituting (30) into (24) and substituting (31) into (25), the relationship between the PW voltage and the CW current can be obtained by

$$
\begin{aligned}
-\mathbf{i}_{\mathrm{cd} 1}^{+1} & =\left[\frac{1}{\left(\omega_{\mathrm{p}} L_{\mathrm{pr}} \alpha_{1}^{+1}\right)}\right] \mathbf{u}_{\mathrm{pq} 1}^{+1}+D_{\mathrm{pd} 1}^{+1}, \\
\mathbf{i}_{\mathrm{cq} 1}^{+1} & =\left[\frac{1}{\left(\omega_{\mathrm{p}} L_{\mathrm{pr}} \beta_{1}^{+1}\right)}\right] \mathbf{u}_{\mathrm{pd} 1}^{+1}+D_{\mathrm{pq} 1}^{+1} .
\end{aligned}
$$

The detailed expressions for $D_{\mathrm{pd} 1}^{+1}$ and $D_{\mathrm{pq} 1}^{+1}$ can be found in Appendix. 1/ $\left(\omega_{\mathrm{p}} L_{\mathrm{pr}} \alpha_{1}^{+1}\right)$ is the transfer function from $\mathbf{u}_{\mathrm{pq} 1}^{+1}$ 
to $-\mathbf{i}_{\mathrm{cd} 1}^{+1}$, and $1 /\left(\omega_{\mathrm{p}} L_{\mathrm{pr}} \beta_{1}^{+1}\right)$ the transfer function from $\mathbf{u}_{\mathrm{pd} 1}^{+1}$ to $\mathbf{i}_{\mathrm{cq} 1}^{+1}$. It is noted that $1 /\left(\omega_{\mathrm{p}} L_{\mathrm{pr}} \alpha_{1}^{+1}\right)$ is equal to $1 /\left(\omega_{\mathrm{p}} L_{\mathrm{pr}} \beta_{1}^{+1}\right)$ according to (A.1). From (32) and (33), $\mathbf{u}_{\mathrm{pd} 1}^{+1}$ and $\mathbf{u}_{\mathrm{p} 1}^{+1}$ can be controlled by $\mathbf{i}_{\mathrm{cq} 1}^{+1}$ and $\mathbf{i}_{\mathrm{cd} 1}^{+1}$, respectively. $D_{\mathrm{pd} 1}^{+1}$ and $D_{\mathrm{pq} 1}^{+1}$ are the disturbance terms, including the cross-coupling disturbance between $\mathrm{d}$ - and q-components of the CW current and the coupling disturbance between the PW and CW, and can be used as the feedforward compensation to improve the dynamic ability of the control loop.

Since the PW fundamental-voltage controller is based on the PW fundamental voltage vector orientation, the $d$-axis of the reference frame $\mathrm{dq}^{+1}$ is forced to align with the PW fundamental-voltage vector, and the references of the $\mathrm{d}$ - and $\mathrm{q}$-components of the $\mathrm{PW}$ fundamental voltage, $\mathbf{u}_{\mathrm{pd} 1}^{+1 *}$ and $\mathbf{u}_{\mathrm{pq} 1}^{+1 *}$, should be set to

$$
\begin{aligned}
& \mathbf{u}_{\mathrm{pd} 1}^{+1 *}=U_{\mathrm{p} 1}^{*}, \\
& \mathbf{u}_{\mathrm{pq} 1}^{+1 *}=0,
\end{aligned}
$$

where $U_{\mathrm{p} 1}^{*}$ is the reference of the PW fundamental voltage amplitude. According to (32)-(34), the PW fundamentalvoltage controller can be obtained as shown in Figure 4.

4.2. Control of $P W$ Harmonic Voltage. From (18), by using the derivation method similar to that in the control of PW fundamental voltage, the relationship between the PW voltage and the CW current in the fifth harmonic reference frame $\left(\mathrm{dq}^{-5}\right)$ can be derived as

$$
\begin{aligned}
\mathbf{i}_{\mathrm{cd} 5}^{-5} & =\left[\frac{1}{\left(5 \omega_{\mathrm{p}} L_{\mathrm{pr}} \alpha_{1}^{-5}\right)}\right] \mathbf{u}_{\mathrm{pq} 5}^{-5}+D_{\mathrm{pd} 5}^{-5}, \\
-\mathbf{i}_{\mathrm{cq} 5}^{-5} & =\left[\frac{1}{\left(5 \omega_{\mathrm{p}} L_{\mathrm{pr}} \beta_{1}^{-5}\right)}\right] \mathbf{u}_{\mathrm{pd} 5}^{-5}+D_{\mathrm{pq} 5}^{-5} .
\end{aligned}
$$

The detailed expressions for $\alpha_{1}^{-5}-\alpha_{4}^{-5}, \beta_{1}^{-5}-\beta_{4}^{-5}, D_{\mathrm{pd} 5}^{-5}$, and $D_{\mathrm{pq} 5}^{-5}$ have been given in Appendix. In (35) and (36), $1 /\left(5 \omega_{\mathrm{p}} L_{\mathrm{pr}} \alpha_{1}^{-5}\right)$ is the transfer function from $u_{\mathrm{pq} 5}^{-5}$ to $i_{\mathrm{cd} 5}^{-5}$, $1 /\left(5 \omega_{\mathrm{p}} L_{\mathrm{pr}} \beta_{1}^{-5}\right)$ the transfer function from $u_{\mathrm{pd} 5}^{-5}$ to $-i_{\mathrm{cq} 5}^{-5}$, and $D_{\mathrm{pd} 5}^{-5}$ and $D_{\mathrm{pq} 5}^{-5}$ the disturbance terms. Therefore, the $d$ - and $q$-components of the PW fifth harmonic voltage, $u_{\mathrm{pd} 5}^{-5}$ and $u_{\mathrm{pq} 5}^{-5}$, can be controlled by $i_{\mathrm{cq} 5}^{-5}$ and $i_{\text {cd5 }}^{-5}$, respectively.

Similarly, the relationship between the PW voltage and the CW current in the seventh harmonic reference frame $\left(\mathrm{dq}^{+7}\right)$ can be obtained from (19) as follows:

$$
\begin{gathered}
-i_{\mathrm{cd} 7}^{+7}=\left[\frac{1}{\left(7 \omega_{\mathrm{p}} L_{\mathrm{pr}} \alpha_{1}^{+7}\right)}\right] u_{\mathrm{pq} 7}^{+7}+D_{\mathrm{pd} 7}^{+7}, \\
i_{\mathrm{cq} 7}^{+7}=\left[\frac{1}{\left(7 \omega_{\mathrm{p}} L_{\mathrm{pr}} \beta_{1}^{+7}\right)}\right] u_{\mathrm{pd} 7}^{+7}+D_{\mathrm{pq} 7}^{+7} .
\end{gathered}
$$

The detailed expressions for $\alpha_{1}^{+7}-\alpha_{4}^{+7}, \beta_{1}^{+7}-\beta_{4}^{+7}, D_{\mathrm{pd} 7}^{+7}$, and $D_{\mathrm{pd} 7}^{+7}$ have been given in Appendix. Similarly, the $\mathrm{d}$ - and $\mathrm{q}$-components of the PW seventh harmonic voltage, $\boldsymbol{u}_{\mathrm{pd} 7}^{+7}$ and $u_{\mathrm{pq} 7}^{+7}$, can be controlled by $i_{\mathrm{cq} 7}^{+7}$ and $i_{\mathrm{cd} 7}^{+7}$, respectively.

In order to eliminate the fifth and seventh harmonic components in the PW voltage, these references of the d- and q-components of the PW harmonic voltage, $u_{\mathrm{pd} 5}^{-5 *}, u_{\mathrm{pq} 5}^{-5 *}$, $u_{\mathrm{pd} 7}^{+7 *}$, and $u_{\mathrm{pq} 7}^{+7 *}$, should be set to

$$
u_{\mathrm{pd} 5}^{-5 *}=u_{\mathrm{pq} 5}^{-5 *}=u_{\mathrm{pd} 7}^{+7 *}=u_{\mathrm{pq} 7}^{+7 *}=0
$$

According to (35)-(38), the PW harmonic-voltage controller can be designed as shown in Figure 4. Since the harmonic component of the $\mathrm{PW}$ voltage is much smaller than the fundamental one, the dynamic performance requirements of the harmonic-voltage controller can be lower than that of the fundamental-voltage controller. Therefore, the disturbance terms $D_{\mathrm{pd} 5}^{-5}, D_{\mathrm{pq} 5}^{-5}, u_{\mathrm{pd} 7}^{+7}$, and $u_{\mathrm{pq}}^{+7}$ are not used as the feedforward compensation of the control loop due to their dependence on the machine parameters. Although the dynamic performance would be compromised, the stability could be guaranteed. Besides, it is noteworthy that the CW current references obtained by the PW harmonic-voltage controller should be transformed to the fundamental reference frame $\left(\mathrm{dq}^{+1}\right)$ according to (4) and (5), so as that the CW current controller can be designed in the reference frame $\mathrm{dq}^{+1}$.

4.3. Design of CW Predictive Current Controller. Since the $\mathrm{CW}$ current references contain both the dc and ac components, the conventional PI controller is not suitable in this case. An improved predictive current control strategy for unbalanced stand-alone doubly fed induction generator (DFIG) has been proposed to track the ac references of the rotor current in [19]. However, such method has not been used in the BDFIG. In this paper, a CW predictive current controller is designed. The proposed current controller is derived in the reference frame $\mathrm{dq}^{+1}$.

From the fifth and sixth parts of (3), according to [10], the $d$ - and $q$-components of the rotor current in the reference frame $\mathrm{dq}^{+1}$ can be simplified as

$$
\begin{aligned}
& i_{\mathrm{rd}}^{+1}=-\frac{L_{\mathrm{pr}} i_{\mathrm{pd}}^{+1}+L_{\mathrm{cr}} i_{\mathrm{cd}}^{+1}}{L_{\mathrm{r}}}-\frac{R_{\mathrm{r}}\left(L_{\mathrm{pr}} i_{\mathrm{pq}}^{+1}+L_{\mathrm{cr}} i_{\mathrm{cq}}^{+1}\right)}{L_{\mathrm{r}}^{2}\left(\omega_{\mathrm{c}}-p_{\mathrm{c}} \omega_{\mathrm{r}}\right)}, \\
& i_{\mathrm{rq}}^{+1}=-\frac{\left(L_{\mathrm{pr}} i_{\mathrm{pq}}^{+1}+L_{\mathrm{cr}} i_{\mathrm{cq}}^{+1}\right)}{L_{\mathrm{r}}} .
\end{aligned}
$$

By substituting (40) and (41) into the third part of (3), the $\mathrm{d}$ - and $\mathrm{q}$-components of the $\mathrm{CW}$ voltage in the reference frame $\mathrm{dq}^{+1}, u_{\mathrm{cd}}^{+1}$ and $u_{\mathrm{cq}}^{+1}$, can be obtained by

$$
\begin{aligned}
& u_{\mathrm{cd}}^{+1}=R_{\mathrm{c}} i_{\mathrm{cd}}^{+1}+\sigma_{\mathrm{c}} L_{\mathrm{c}} s i_{\mathrm{cd}}^{+1}+D_{\mathrm{cd}}^{+1}, \\
& u_{\mathrm{cq}}^{+1}=\left(R_{\mathrm{c}}+\frac{R_{\mathrm{r}} L_{\mathrm{cr}}^{2} \omega_{\mathrm{c}}}{L_{\mathrm{r}}^{2}\left(\omega_{\mathrm{c}}-p_{\mathrm{c}} \omega_{\mathrm{r}}\right)}\right) i_{\mathrm{cq}}^{+1}+\sigma_{\mathrm{c}} L_{\mathrm{c}} s i_{\mathrm{cq}}^{+1}+D_{\mathrm{cq}}^{+1},
\end{aligned}
$$

where $\sigma_{\mathrm{c}}=1-L_{\mathrm{cr}}^{2} /\left(L_{\mathrm{c}} L_{\mathrm{r}}\right)$ is the leakage constant of the CW and $D_{\mathrm{cd}}^{+1}$ and $D_{\mathrm{cq}}^{+1}$ are the disturbance terms indicating the cross coupling between $\mathrm{d}$ - and q-components of the $\mathrm{CW}$ current and the indirect coupling between the PW and CW. The detailed expressions for $D_{\mathrm{cd}}^{+1}$ and $D_{\mathrm{cq}}^{+1}$ can be seen in Appendix. The CW frequency $\omega_{c}$ is obtained by using (2).

Discretizing (42) and (43), the CW voltage at the $k$ th sampling period can be expressed as 


$$
\begin{aligned}
u_{\mathrm{cd}}^{+1}(k)= & {\left[\frac{R_{\mathrm{c}} i_{\mathrm{cd}}^{+1}(k)+\sigma_{\mathrm{c}} L_{\mathrm{c}} \Delta i_{\mathrm{cd}}^{+1}(k)}{T_{\mathrm{s}}}\right]+D_{\mathrm{cd}}^{+1}(k), } \\
u_{\mathrm{cq}}^{+1}(k)= & \left(R_{\mathrm{c}}+\frac{R_{\mathrm{r}} L_{\mathrm{cr}}^{2} \omega_{\mathrm{c}}}{L_{\mathrm{r}}^{2}\left(\omega_{\mathrm{c}}-p_{\mathrm{c}} \omega_{\mathrm{r}}\right)}\right) i_{\mathrm{cq}}^{+1}(k) \\
& +\frac{\sigma_{\mathrm{c}} L_{\mathrm{c}} \Delta i_{\mathrm{cq}}^{+1}(k)}{T_{\mathrm{s}}}+D_{\mathrm{cq}}^{+1}(k),
\end{aligned}
$$

where $\Delta i_{\mathrm{cd}}^{+1}$ and $\Delta i_{\mathrm{cq}}^{+1}$ are the differences of the CW d-and q-component currents between two adjacent sampling periods and $T_{\mathrm{s}}$ is the sampling interval. $\Delta i_{\mathrm{cd}}^{+1}(k)$ and $\Delta i_{\mathrm{cq}}^{+1}(k)$ are defined as

$$
\begin{aligned}
& \Delta i_{\mathrm{cd}}^{+1}(k)=i_{\mathrm{cd}}^{+1}(k+1)-i_{\mathrm{cd}}^{+1}(k), \\
& \Delta i_{\mathrm{cq}}^{+1}(k)=i_{\mathrm{cq}}^{+1}(k+1)-i_{\mathrm{cq}}^{+1}(k) .
\end{aligned}
$$

It is difficult to predict accurately the actual CW currents $i_{\mathrm{cd}}^{+1}(k+1)$ and $i_{\mathrm{cq}}^{+1}(k+1)$. However, the target of the $\mathrm{CW}$ predictive current controller is to minimize the CW current errors at the $(k+1)$ th sampling period; therefore, the reference CW currents $i_{\mathrm{cd}}^{+1 *}(k+1)$ and $i_{\mathrm{cq}}^{+1 *}(k+1)$ at the $(k+1)$ th sampling period could be used to replace the actual ones in (46). The reference CW currents at the $(k+1)$ th sampling period can be obtained by the linear extrapolation method as follows:

$$
\begin{aligned}
& i_{\mathrm{cd}}^{+1 *}(k+1)=2 i_{\mathrm{cd}}^{+1 *}(k)-i_{\mathrm{cd}}^{+1 *}(k-1), \\
& i_{\mathrm{cq}}^{+1 *}(k+1)=2 i_{\mathrm{cq}}^{+1 *}(k)-i_{\mathrm{cq}}^{+1 *}(k-1) .
\end{aligned}
$$

Hence, the differences of the CW currents between the $(k+1)$ th and the $k$ th sampling periods can be expressed as

$$
\begin{aligned}
\Delta i_{\mathrm{cd}}^{+1}(k) & =2 i_{\mathrm{cd}}^{+1 *}(k)-i_{\mathrm{cd}}^{+1 *}(k-1)-i_{\mathrm{cd}}^{+1}(k), \\
\Delta i_{\mathrm{cq}}^{+1}(k) & =2 i_{\mathrm{cq}}^{+1 *}(k)-i_{\mathrm{cq}}^{+1 *}(k-1)-i_{\mathrm{cq}}^{+1}(k) .
\end{aligned}
$$

By substituting (48) to (44) and (45), the $d-$ and q-component references of the CW voltage, $u_{\mathrm{cd}}^{+1 *}(k)$ and $u_{\mathrm{cq}}^{+1 *}(k)$, can be obtained. The three-phase CW voltage references can be calculated according to the coordinate transformation method proposed in [17], which requires the estimated rotor position $\widehat{\theta}_{\mathrm{r}}$ and the reference of the PW voltage phase $\theta_{\mathrm{p}}^{*}$.

4.4. Extraction of PW Harmonic Voltage. According to the analysis in Section 3, under nonlinear load conditions, the PW voltage contains significant harmonic components, especially the fifth and the seventh harmonics. In order to suppress these harmonics in the PW voltage, these harmonics need to be extracted accurately and then input to the PW harmonic-voltage controller. In the previous studies for control of the stand-alone DFIG under nonlinear load conditions $[13,14]$, a band-pass filter is employed to extract the harmonic components, but the dynamic response is highly degraded because the frequencies of the fundamental, fifth, and seventh harmonics are relatively close.

In this paper, a MSOGI [18] and a stationary-frame phase-locked loop (PLL) [20] are employed to estimate these harmonic components. Hence, the scheme for the PW harmonic voltage extraction is called the MSOGI-PLL, as shown in Figure 5. The MSOGI consists of three dual second-order generalized integrators (DSOGIs), which are used to extract the fundamental, fifth harmonic, and seventh harmonic components of the PW voltage, respectively. The stationary-frame PLL is employed to estimate the fundamental frequency and phase angle based on the $\alpha$ - and $\beta$-components of the fundamental PW voltage. The resonance frequencies of the three DSOGIs are 1,5, and 7 times the fundamental frequency, respectively. The variable $k$ is the damping factor of the first DSOGI, and the damping factors of the second and the third DSOGIs are set to $k / 5$ and $k / 7$, respectively, in order to guarantee the same bandwidth for all the DSOGIs.

4.5. Rotor Speed Observer. This paper employs an improved rotor speed observer to estimate the rotor speed [21]. By making integration of (1), it can get the relationship among the rotor position $\theta_{r}$, the PW voltage vector angle $\theta_{p}$, and the CW current vector angle $\theta_{\mathrm{c}}$, as expressed by

$$
\left(p_{\mathrm{p}}+p_{\mathrm{c}}\right) \theta_{\mathrm{r}}=\theta_{\mathrm{p}}+\theta_{\mathrm{c}}
$$

From (49), the difference $\Delta \theta_{\mathrm{r}}$ between the actual and estimated rotor position in the vicinity of the equilibrium point can be derived as

$$
\begin{aligned}
\left(p_{\mathrm{p}}+p_{\mathrm{c}}\right) \Delta \theta_{\mathrm{r}} & =\left(p_{\mathrm{p}}+p_{\mathrm{c}}\right)\left(\theta_{\mathrm{r}}-\hat{\theta}_{\mathrm{r}}\right)=\left(\theta_{\mathrm{p}}+\theta_{\mathrm{c}}\right)-\left(p_{\mathrm{p}}+p_{\mathrm{c}}\right) \hat{\theta}_{\mathrm{r}} \\
& \approx \sin \left[\left(\theta_{\mathrm{p}}+\theta_{\mathrm{c}}\right)-\left(p_{\mathrm{p}}+p_{\mathrm{c}}\right) \hat{\theta}_{\mathrm{r}}\right] .
\end{aligned}
$$

According to (50), a stationary-frame PLL can be employed to obtain the estimated rotor position $\widehat{\theta}_{\mathrm{r}}$ and rotor speed $\widehat{\omega}_{\mathrm{r}}$. The basic rotor speed observer is proposed, as shown in Figure 6, which is based on the three-phase PW voltage and the three-phase CW current.

According to the analysis in Section 3, a nonlinear load can result in distorted PW voltage and CW current, which would cause inaccurate rotor position and speed estimation by using the basic rotor speed observer. In order to overcome this problem, the PW voltage and CW current need to be prefiltered before their input to the basic rotor speed observer. Fortunately, as it can be seen from Figure 5, the $\alpha$ - and $\beta$-components of the PW fundamental voltage, $u_{\mathrm{p} \alpha 1}$ and $u_{\mathrm{p} \beta 1}$, have been extracted by the MSOGI-PLL. In addition, the two low-pass filters are employed to adaptively filter the CW current, in order to obtain the $\alpha$ - and $\beta$-components, $i_{\mathrm{c} \alpha 1}$ and $i_{c \beta 1}$, of the CW fundamental current. The resonance frequency of the two SOGIs is derived from (2). Finally, the quantities $u_{\mathrm{p} \alpha 1}, u_{\mathrm{p} \beta 1}, i_{\mathrm{c} \alpha 1}$, and $i_{\mathrm{c} \beta 1}$ are input to the basic rotor speed observer to obtain the accurate rotor position and speed. The improved rotor speed observer is presented in Figure 7.

\section{Experimental Results}

5.1. Experimental Setup. The experimental setup is shown in Figure 8 . The experiments are performed on a $35-\mathrm{kVA}$ prototype BDFIG, whose detailed parameters are listed in Table 1. A 


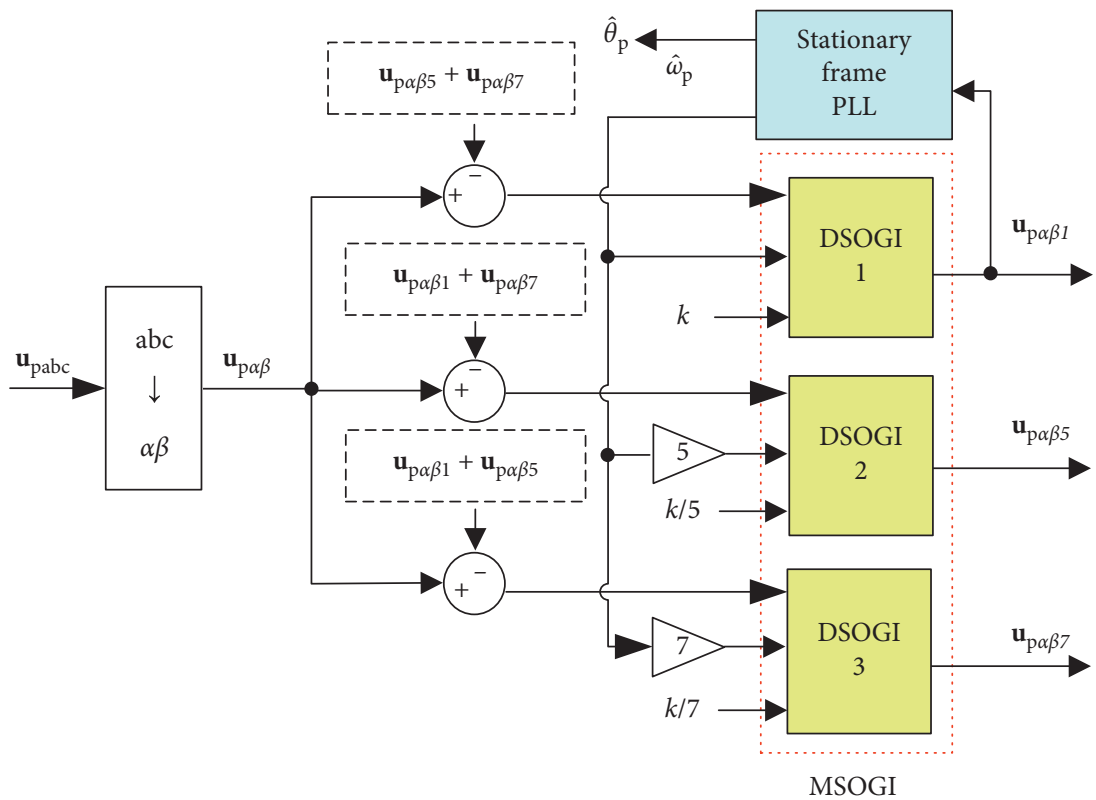

Figure 5: The MSOGI-PLL for the extraction of PW harmonic voltage.

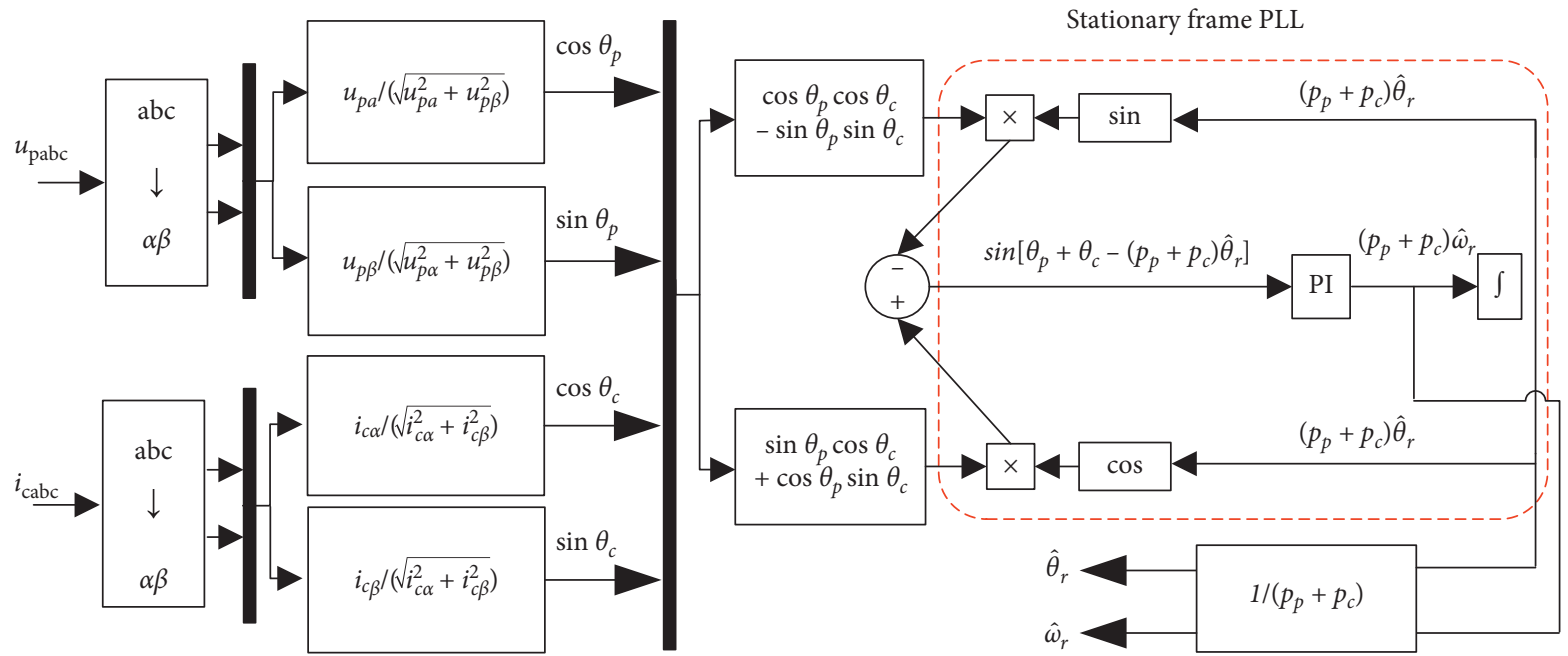

FIGURE 6: Structure of the basic rotor speed observer.

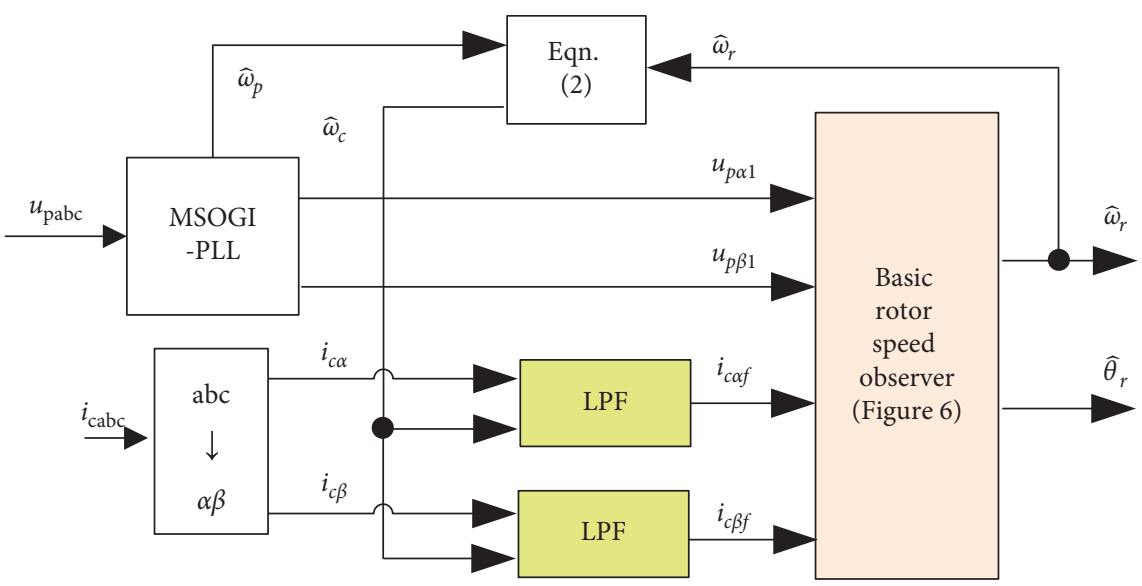

FIgURE 7: The improved rotor speed observer for the stand-alone BDFIG under nonlinear load conditions. 


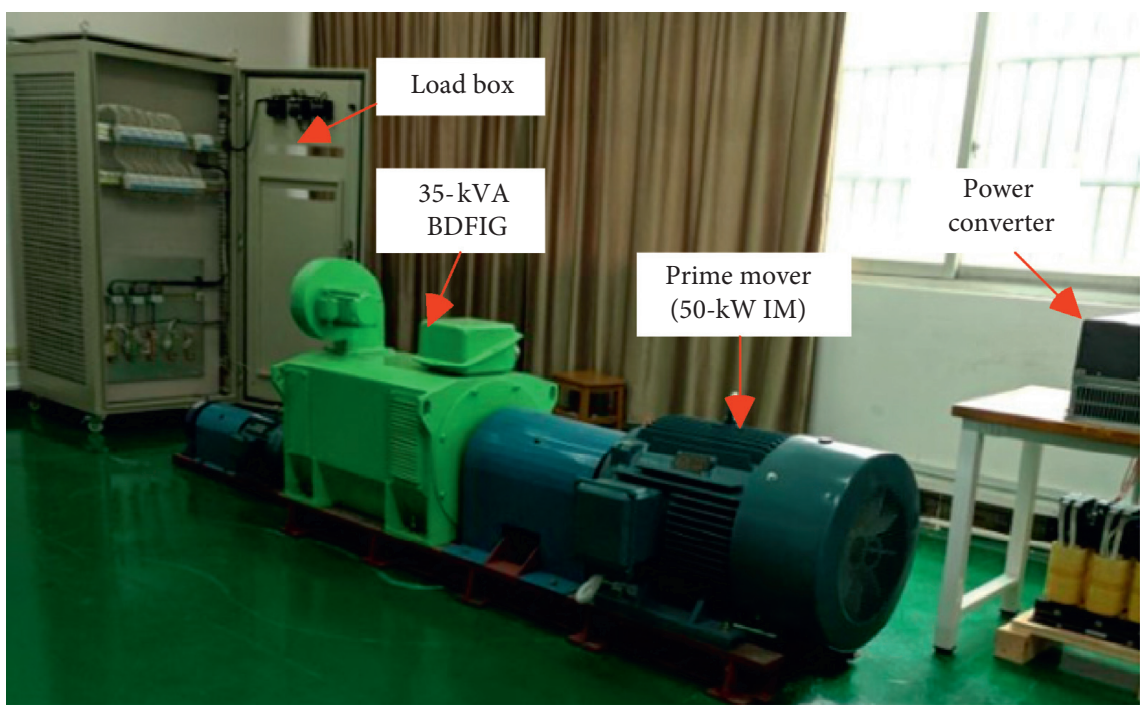

FIgURE 8: Photograph of the experimental setup.

$50-\mathrm{kW}$ three-phase induction motor is used as a prime mover. The reference RMS and frequency of the PW line voltage are set to $380 \mathrm{~V}$ and $50 \mathrm{~Hz}$, respectively. The nonlinear load is a threephase diode rectifier supplying a resistive load of $25 \Omega$.

\subsection{Performance Test of the Rotor Speed Observer. The per-} formance test of the rotor speed observer is carried out without the activation of the PW harmonic-voltage controller, which is regarded as the most demanding operation condition for the observer due to the severely distorted PW voltage and CW current. The test results are shown in Figure 9.

At the beginning, the stand-alone BDFIG runs under noload condition at the rotor speed of $600 \mathrm{rpm}$. At $0.44 \mathrm{~s}$, the connection of the nonlinear load leads to significant distortion of the PW voltage and CW current. Due to a sudden connected nonlinear load at $0.44 \mathrm{~s}$, the amplitude of PW voltage drops from 537 to $98 \mathrm{~V}$, which results in the amplitude of CW current being increased from 30 to $96 \mathrm{~A}$ under the control of the system. And, a severe transient drop of the rotor speed occurs due to a sudden increased load on the prime mover. Between 2.4 and $10 \mathrm{~s}$, the rotor speed rises from 600 to $930 \mathrm{rpm}$ and then drops to $890 \mathrm{rpm}$. During the whole process, the basic and improved rotor speed observers give a similar response speed. Therefore, in the improved observer, the prefiltering of the PW voltage and the CW current does not result in the dynamic performance degradation. Besides, the rotor speed estimated by the basic observer is always with a fluctuation of about $24 \mathrm{rpm}$ peakto-peak value, whereas the fluctuation of the improved observer is significantly reduced to about $4 \mathrm{rpm}$. Hence, the improved observer can provide satisfactory performance for the stand-alone BDFIG with nonlinear loads.

5.3. Experimental Results under Constant Rotor Speed. Figure 10 presents the experimental results with and without the activation of the PW harmonic-voltage controller at the rotor speed of $600 \mathrm{rpm}$. It can be seen that, without the
TABLE 1: Main parameters of the prototype BDFIG.

\begin{tabular}{lc}
\hline Parameter & Value \\
\hline Capacity & $35 \mathrm{kVA}$ \\
Speed range & $600-1200 \mathrm{rpm}$ \\
$\mathrm{PW}$ and CW pole pairs & 1,3 \\
$\mathrm{PW}$-rated voltage and current & $380 \mathrm{~V}, 53 \mathrm{~A}$ \\
$\mathrm{CW}$ voltage and current range & $0-350 \mathrm{~V}, 0-50 \mathrm{~A}$ \\
$\mathrm{PW}, \mathrm{CW}$, and rotor resistances & $0.5102 \Omega, 0.3350 \Omega$, \\
& $0.4129 \Omega$ \\
PW, CW, and rotor self-inductances & $0.4865 \mathrm{H}, 0.0312 \mathrm{H}$, \\
$\begin{array}{l}\text { Mutual inductance between PW and } \\
\text { rotor }\end{array}$ & $0.2034 \mathrm{H}$ \\
$\begin{array}{l}\text { Mutual inductance between CW and } \\
\text { rotor }\end{array}$ & $0.4128 \mathrm{H}$ \\
\hline
\end{tabular}

activation of the PW harmonic-voltage controller, the amplitude of the fifth harmonic voltage reaches about $30 \mathrm{~V}$ and that of the seventh harmonic voltage to $25 \mathrm{~V}$. After the activation of the PW harmonic-voltage controller, some harmonics are injected into the CW current to compensate the distortion of the PW voltage, and consequently the amplitudes of the fifth and seventh harmonic voltages are reduced to nearly zero within $50 \mathrm{~ms}$. With the activation of the PW harmonic-voltage controller, the total harmonic distortion (THD) of the PW voltage is significantly reduced from $8.1 \%$ to $2.6 \%$. And, it can be noted that, without the activation of the PW harmonic-voltage controller, the amplitudes of the seventh and nineteenth harmonic voltages are almost the same. Actually, the nineteenth harmonic component in PW voltage is mainly caused by the PWM modulation of LSC. Since this paper focuses on eliminating the harmonics produced by nonlinear loads rather than those caused by the modulation of power converters, the compensation for the nineteenth harmonic component of PW voltage is not considered in the design of the control scheme. Besides, after the activation of the PW harmonic-voltage 


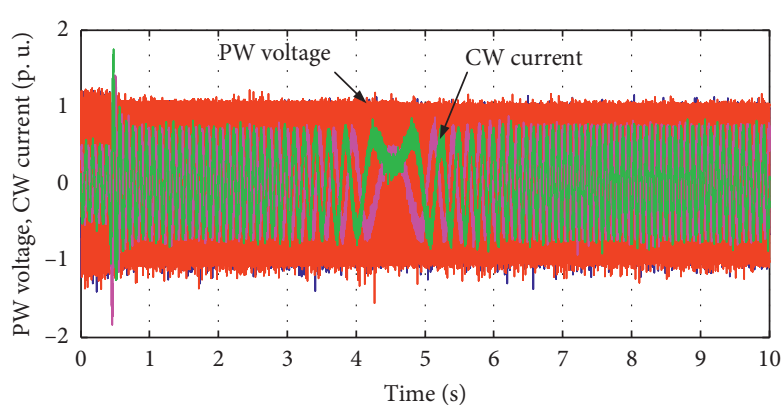

(a)

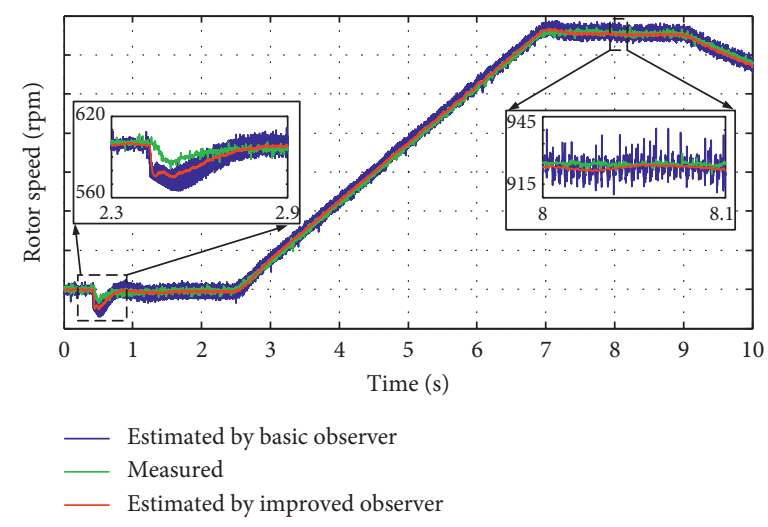

(c)

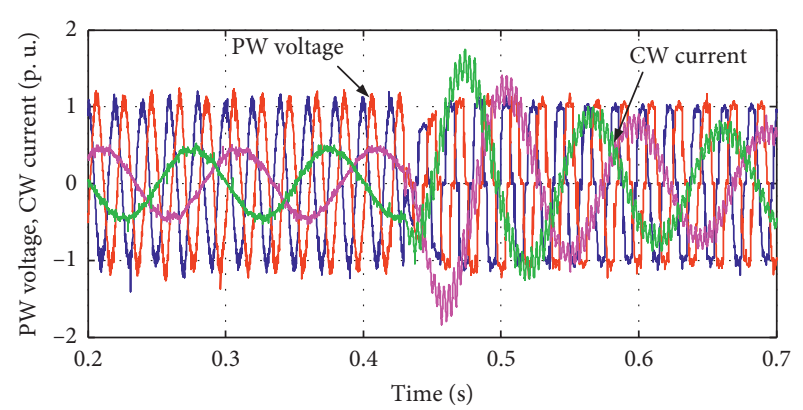

(b)

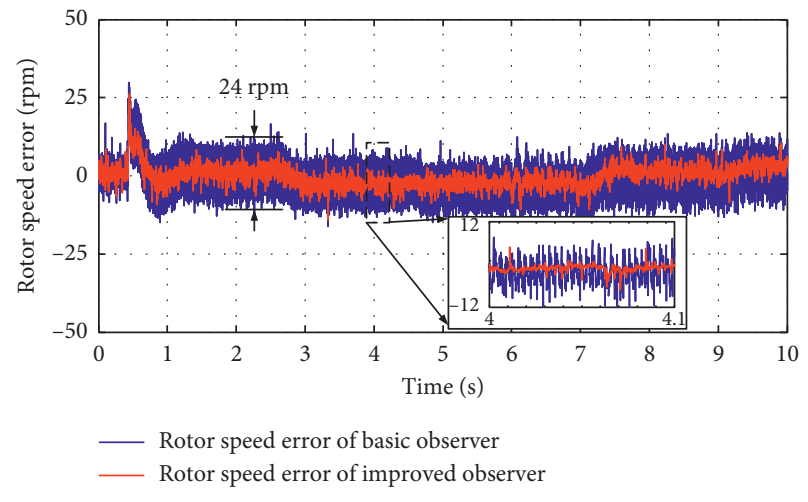

(d)

FIgURE 9: Test results of the rotor speed observer without the PW harmonic-voltage controller being activated. (a) PW voltage $(1$ p.u. $=500 \mathrm{~V})$ and CW current (1 p.u. $=60 \mathrm{~A})$. (b) Detailed view of (a). (c) Rotor speeds observed by the basic and improved observers. (d) Rotor speed errors of the basic and improved observers.

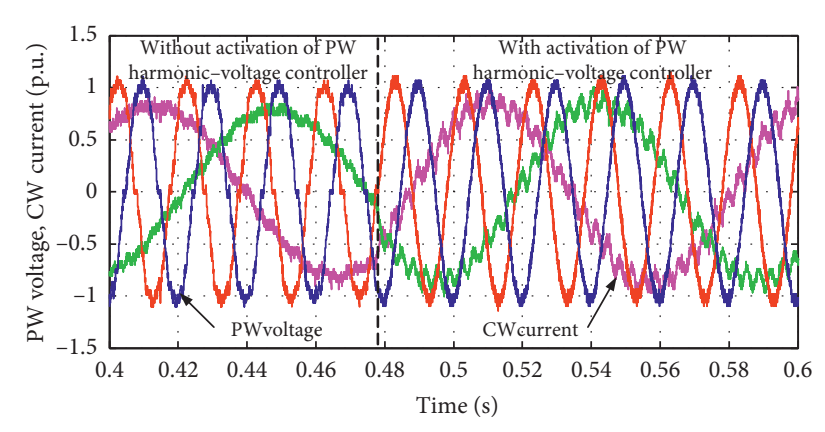

(a)

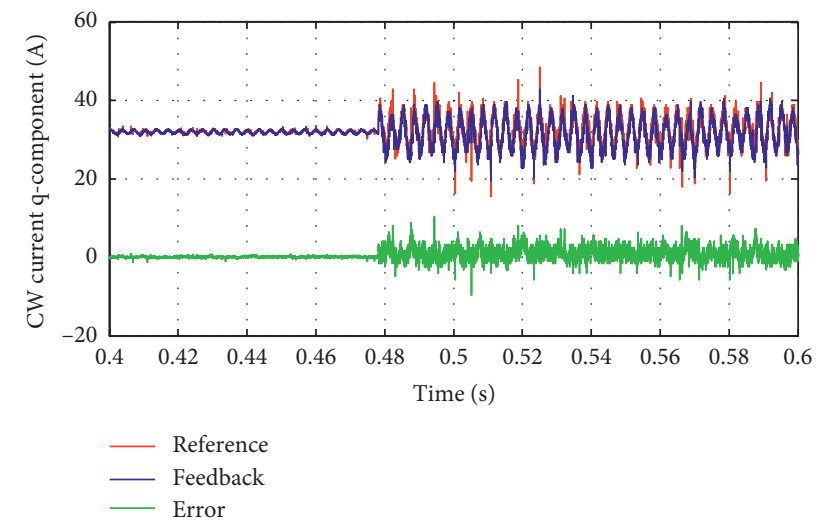

(c)

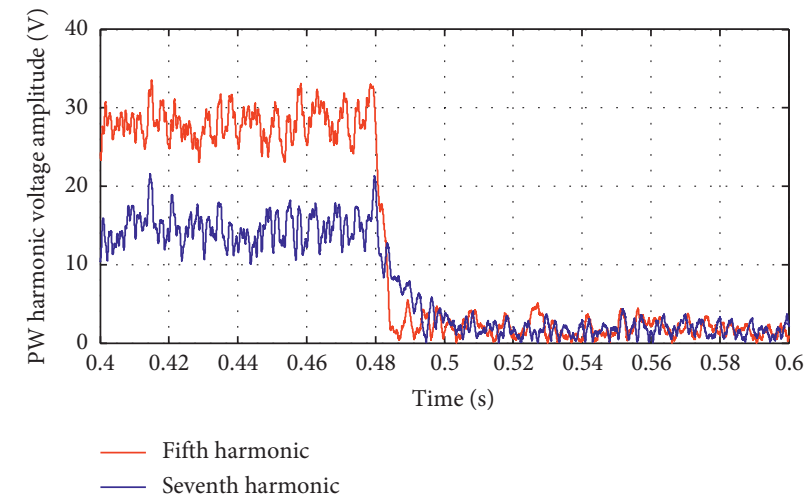

(b)

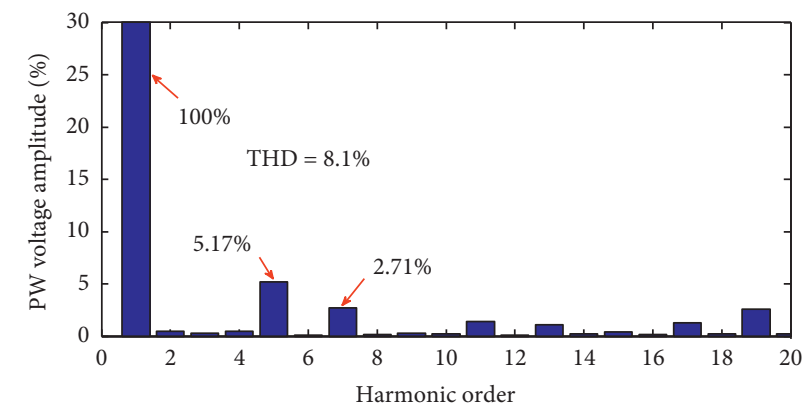

FIgURE 10: Continued. 


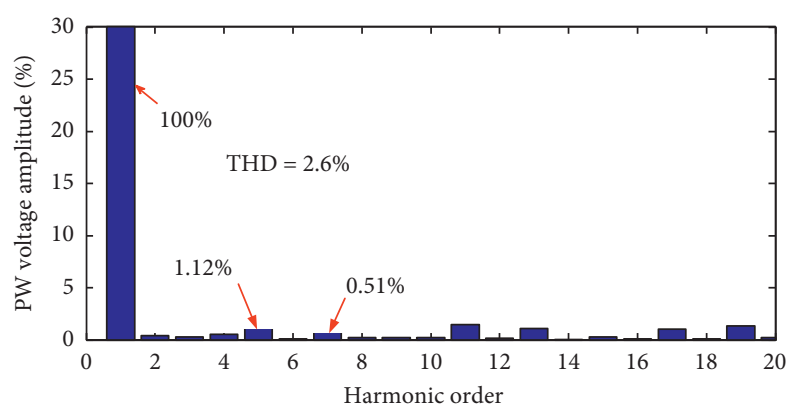

(e)

FIGURE 10: Experimental results with and without the activation of the PW harmonic-voltage controller at the rotor speed of $600 \mathrm{rpm}$. (a) PW line voltage $(1 \mathrm{p} \mathrm{u}=500 \mathrm{~V})$ and $\mathrm{CW}$ phase current $(1 \mathrm{p} \mathrm{u}=60 \mathrm{~A})$. (b) Amplitude of PW harmonic voltage. (c) Reference, feedback, and error of the q-component of the CW current. (d) Harmonic spectrum of PW voltage before activation of the PW harmonic-voltage controller. (e) Harmonic spectrum of PW voltage after activation of the PW harmonic-voltage controller.

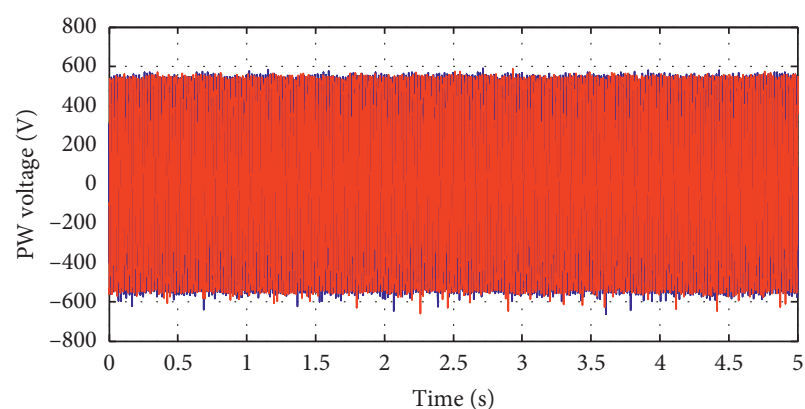

(a)

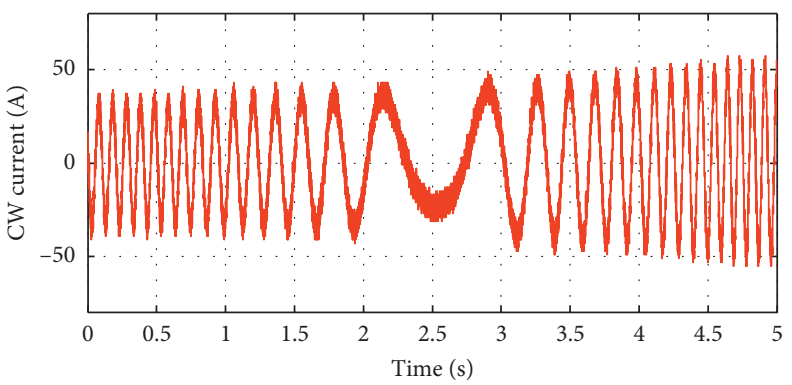

(c)

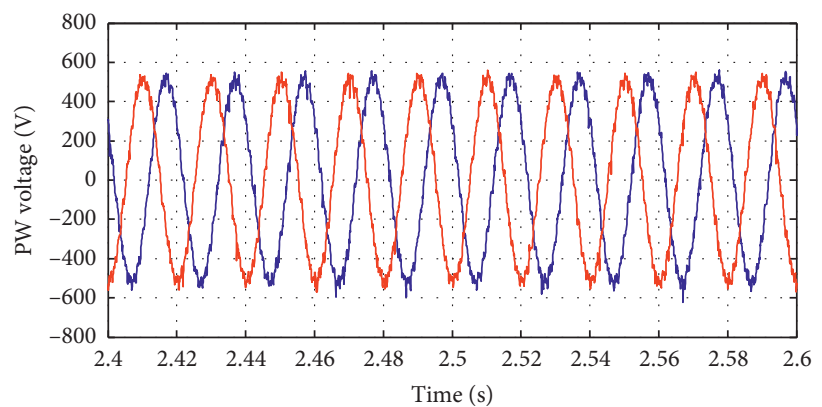

(b)

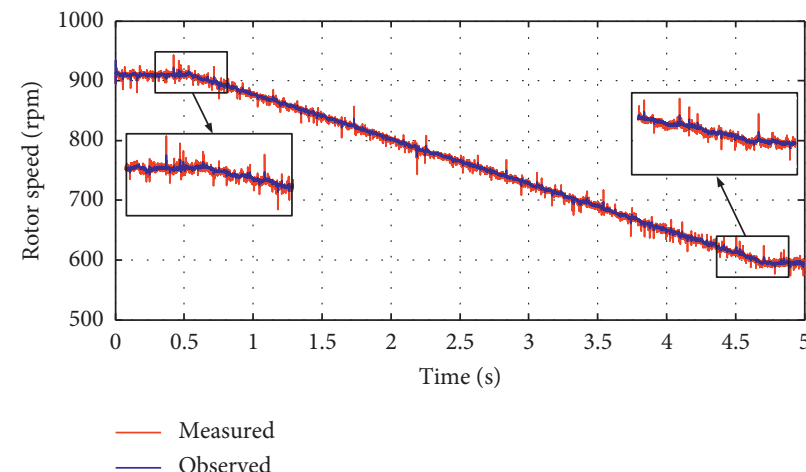

(d)

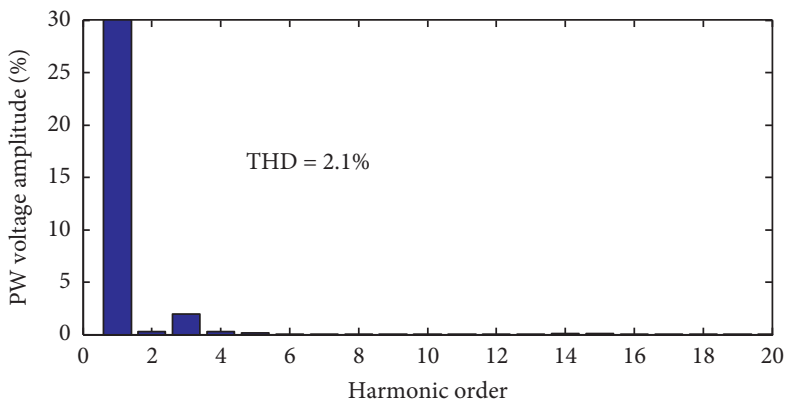

(e)

FIGURE 11: Experimental results with the activation of the PW harmonic-voltage controller during the rotor speed dropping from $900 \mathrm{rpm}$ (supersynchronous speed) to $600 \mathrm{rpm}$ (subsynchronous speed). (a) PW line voltage. (b) Enlarged view of the PW line voltage between $2.4 \mathrm{~s}$ and $2.6 \mathrm{~s}$ (c) CW phase current. (d) Measured and observed rotor speed. (e) Harmonic spectrum of the PW voltage at the rotor speed of $900 \mathrm{rpm}$. 
controller, the reference of the $q$-component of the $\mathrm{CW}$ current is composed of ac and dc parts and can be well tracked by the proposed CW predictive current controller. Due to the limited number of analog output channels in the control system, the quantities about the $\mathrm{CW}$ current $\mathrm{d}$-component are not acquired and shown.

5.4. Experimental Results under Variable Rotor Speed. In order to validate the dynamic performance of the control system under the variable rotor speed, the experiments have been carried out in the typical rotor speed range (from the supersynchronous speed $900 \mathrm{rpm}$ to the subsynchronous speed $600 \mathrm{rpm}$ ). The experimental results are presented in Figure 11. Through the whole process, the amplitude and frequency of the PW voltage are almost constant. The rotor speed can be estimated very well by using the improved rotor speed observer. The THD of the PW voltage at the rotor speed of $900 \mathrm{rpm}$ is about $2.1 \%$ and that at $600 \mathrm{rpm}$ has been presented in Figure 10(e).

\section{Conclusion}

This paper presents an enhanced sensorless control scheme for the stand-alone BDFIG with nonlinear loads. The PW fundamental-voltage controller, based on the PW fundamental-voltage vector orientation, is used to control the amplitude and frequency of the PW fundamental voltage. The PW harmonic-voltage controller is employed to eliminate the harmonics of the PW voltage, especially the fifth and seventh ones. A rotor speed observer is proposed to estimate the rotor position and speed from the PW voltage and CW current. The predictive control method is introduced to this system to regulate the CW current. Comprehensive experiments demonstrate that the proposed scheme can significantly improve the performance of the stand-alone BDFIG under nonlinear loads.

\section{Appendix}

$$
\begin{aligned}
& \alpha_{1}^{n}=\beta_{1}^{n}=\frac{L_{\mathrm{r}} L_{\mathrm{cr}}\left(n \omega_{\mathrm{p}}-p_{\mathrm{p}} \omega_{\mathrm{r}}\right)^{2}+L_{\mathrm{cr}}\left(L_{\mathrm{r}} s^{2}+R_{\mathrm{r}} s\right)}{\left(L_{\mathrm{r}} s+R_{\mathrm{r}}\right)^{2}+L_{\mathrm{r}}^{2}\left(n \omega_{\mathrm{p}}-p_{\mathrm{p}} \omega_{\mathrm{r}}\right)^{2}}, \\
& \alpha_{2}^{n}=\beta_{2}^{n}=-\frac{R_{\mathrm{r}} L_{\mathrm{cr}}\left(n \omega_{\mathrm{p}}-p_{\mathrm{p}} \omega_{\mathrm{r}}\right)}{\left(L_{\mathrm{r}} s+R_{\mathrm{r}}\right)^{2}+L_{\mathrm{r}}^{2}\left(n \omega_{\mathrm{p}}-p_{\mathrm{p}} \omega_{\mathrm{r}}\right)^{2}}, \\
& \alpha_{3}^{n}=\beta_{3}^{n}=-\frac{L_{\mathrm{r}} L_{\mathrm{pr}}\left(n \omega_{\mathrm{p}}-p_{\mathrm{p}} \omega_{\mathrm{r}}\right)^{2}+L_{\mathrm{pr}}\left(L_{\mathrm{r}} s^{2}+R_{\mathrm{r}} s\right)}{\left(L_{\mathrm{r}} s+R_{\mathrm{r}}\right)^{2}+L_{\mathrm{r}}^{2}\left(n \omega_{\mathrm{p}}-p_{\mathrm{p}} \omega_{\mathrm{r}}\right)^{2}}, \\
& \alpha_{4}^{n}=\beta_{4}^{n}=-\frac{R_{\mathrm{r}} L_{\mathrm{pr}}\left(n \omega_{\mathrm{p}}-p_{\mathrm{p}} \omega_{\mathrm{r}}\right)}{\left(L_{\mathrm{r}} s+R_{\mathrm{r}}\right)^{2}+L_{\mathrm{r}}^{2}\left(n \omega_{\mathrm{p}}-p_{\mathrm{p}} \omega_{\mathrm{r}}\right)^{2}},
\end{aligned}
$$

$$
\begin{aligned}
& D_{\mathrm{pd} 1}^{+1}=-\frac{\left[L_{\mathrm{pr}} \alpha_{2}^{+1} i_{\mathrm{cq} 1}^{+1}+\left(L_{\mathrm{p}}+L_{\mathrm{pr}} \alpha_{3}^{+1}\right) i_{\mathrm{pd} 1}^{+1}+L_{\mathrm{pr}} \alpha_{4}^{+1} i_{\mathrm{pq} 1}^{+1}\right]}{\left(L_{\mathrm{pr}} \alpha_{1}^{+1}\right)}, \\
& D_{\mathrm{pq} 1}^{+1}=\frac{\left[L_{\mathrm{pr}} \beta_{2}^{+1} i_{\mathrm{cd} 1}^{+1}+\left(L_{\mathrm{p}}+L_{\mathrm{pr}} \beta_{3}^{+1}\right) i_{\mathrm{pq} 1}^{+1}+L_{\mathrm{pr}} \beta_{4}^{+1} i_{\mathrm{pd} 1}^{+1}\right]}{\left(L_{\mathrm{pr}} \beta_{1}^{+1}\right)},
\end{aligned}
$$

$$
D_{\mathrm{pd} 5}^{-5}=\frac{\left[L_{\mathrm{pr}} \alpha_{2}^{-5} i_{\mathrm{cq} 5}^{-5}+\left(L_{\mathrm{p}}+L_{\mathrm{pr}} \alpha_{3}^{-5}\right) i_{\mathrm{pd} 5}^{-5}+L_{\mathrm{pr}} \alpha_{4}^{-5} i_{\mathrm{pq} 5}^{-5}\right]}{\left(L_{\mathrm{pr}} \alpha_{1}^{-5}\right)},
$$

$$
D_{\mathrm{pq} 5}^{-5}=\frac{-\left[L_{\mathrm{pr}} \beta_{2}^{-5} i_{\mathrm{cd} 5}^{-5}+\left(L_{\mathrm{p}}+L_{\mathrm{pr}} \beta_{3}^{-5}\right) i_{\mathrm{pq} 5}^{-5}+L_{\mathrm{pr}} \beta_{4}^{-5} i_{\mathrm{pd} 5}^{-5}\right]}{\left(L_{\mathrm{pr}} \beta_{1}^{-5}\right)},
$$

$$
D_{\mathrm{pd} 7}^{+7}=\frac{-\left[L_{\mathrm{pr}} \alpha_{2}^{+7} i_{\mathrm{cq} 7}^{+7}+\left(L_{\mathrm{p}}+L_{\mathrm{pr}} \alpha_{3}^{+7}\right) i_{\mathrm{pd} 7}^{+7}+L_{\mathrm{pr}} \alpha_{4}^{+7} i_{\mathrm{pq}}^{+7}\right]}{\left(L_{\mathrm{pr}} \alpha_{1}^{+7}\right)}
$$

$$
D_{\mathrm{pq} 7}^{+7}=\frac{\left[L_{\mathrm{pr}} \beta_{2}^{+7} i_{\mathrm{cd} 7}^{+7}+\left(L_{\mathrm{p}}+L_{\mathrm{pr}} \beta_{3}^{+7}\right) i_{\mathrm{pq} 7}^{+7}+L_{\mathrm{pr}} \beta_{4}^{+7} i_{\mathrm{pd} 7}^{+7}\right]}{\left(L_{\mathrm{pr}} \beta_{1}^{+7}\right)}
$$

$$
\begin{aligned}
& D_{\mathrm{cd}}^{+1}=-\omega_{\mathrm{c}} \frac{L_{\mathrm{pr}} L_{\mathrm{cr}} i_{\mathrm{pq}}^{+1}}{L_{\mathrm{r}}}, \\
& D_{\mathrm{cq}}^{+1}=-\omega_{\mathrm{c}} \sigma_{\mathrm{c}} L_{\mathrm{c}} i_{\mathrm{cd}}^{+1}+\frac{L_{\mathrm{pr}} L_{\mathrm{cr}} \omega_{\mathrm{c}}}{L_{\mathrm{r}}} i_{\mathrm{pd}}^{+1}+\frac{R_{\mathrm{r}} L_{\mathrm{pr}} L_{\mathrm{cr}} \omega_{\mathrm{c}}}{L_{\mathrm{r}}^{2}\left(\omega_{\mathrm{c}}-p_{\mathrm{c}} \omega_{\mathrm{r}}\right)} i_{\mathrm{pq}}^{+1} .
\end{aligned}
$$

In (A.1)-(A.4), the parameter $n$ corresponds to $+1,-5$, or +7 for fundamental, fifth, and seventh components.

\section{Data Availability}

The data used to support the findings of this study are included within the article.

\section{Conflicts of Interest}

The authors declare that they have no conflicts of interest.

\section{References}

[1] R. A. McMahon, P. C. Roberts, X. Wang, and P. J. Tavner, "Performance of BDFM as generator and motor," IEE Proceedings Electric Power Applications, vol. 153, no. 2, pp. 289-299, 2006.

[2] F. Xiong and X. Wang, "Design of a low-harmonic-content wound rotor for the brushless doubly fed generator," IEEE Transactions on Energy Conversion, vol. 29, no. 1, pp. 158-168, 2014.

[3] Y. Liu, W. Ai, B. Chen, and K. Chen, "Control design of the brushless doubly-fed machines for stand-alone VSCF ship 
shaft generator systems," Journal of Power Electronics, vol. 16, no. 1, pp. 259-267, 2016.

[4] S. Shao, E. Abdi, F. Barati, and R. A. McMahon, "Stator-fluxoriented vector control for brushless doubly-fed induction generator," IEEE Trans. Ind. Electron.vol. 56, no. 10, pp. 4220-4228, 2009.

[5] S. Shao, T. Long, E. Abdi, and R. A. McMahon, "Dynamic control of the brushless doubly fed induction generator under unbalanced operation," IEEE Transactions on Industrial Electronics, vol. 60, no. 6, pp. 2465-2476, 2013.

[6] J. Chen, W. Zhang, B. Chen, and Y. Ma, "Improved vector control of brushless doubly fed induction generator under unbalanced grid conditions for offshore wind power generation," IEEE Transactions on Energy Conversion, vol. 31, no. 1, pp. 293-302, 2016.

[7] S. Tohidi, H. Oraee, M. R. Zolghadri, S. Shao, and P. Tavner, "Analysis and enhancement of low-voltage ride-through capability of brushless doubly fed induction generator," IEEE Transactions on Industrial Electronics, vol. 60, no. 3, pp. 11461155, 2013.

[8] S. Ademi and M. Jovanović, "A novel sensorless speed controller design for doubly-fed reluctance wind turbine generators," Energy Conversion and Management, vol. 120, pp. 229-237, 2016.

[9] S. Ademi, M. G. Jovanovic, H. Chaal, and W. Cao, "A new sensorless speed control scheme for doubly fed reluctance generators," IEEE Transactions on Energy Conversion, vol. 31, no. 3, pp. 993-1001, 2016.

[10] Y. Liu, B. Chen, G. Luo, W. Ai, and K. Chen, "Control design and experimental verification of the brushless doubly-fed machine for stand-alone power generation applications," IET Electric Power Applications, vol. 10, no. 1, pp. 25-35, 2016.

[11] X. Wei, M. Cheng, W. Wang, P. Han, and R. Luo, "Direct voltage control of dual-stator brushless doubly fed induction generator for stand-alone wind energy conversion systems," IEEE Trans. Magn., vol. 52, no. 7, 2016.

[12] X. Wang, H. Lin, and Z. Wang, "Transient control of the reactive current for the line-side converter of the brushless doubly-fed induction generator in stand-alone operation," IEEE Transactions on Power Electronics, vol. 32, no. 10, pp. 8193-8203, 2017.

[13] V.-T. Phan and H.-H. Lee, "Control strategy for harmonic elimination in stand-alone DFIG applications with nonlinear loads," IEEE Transactions on Power Electronics, vol. 26, no. 9, pp. 2662-2675, 2011.

[14] V.-T. Phan and H.-H. Lee, "Performance enhancement of stand-alone DFIG systems with control of rotor and load side converters using resonant controllers," IEEE Transactions on Industry Applications, vol. 48, no. 1, pp. 199-210, 2012.

[15] V.-T. Phan, D.-T. Nguyen, Q.-N. Trinh, C.-L. Nguyen, and T. Logenthiran, "Harmonics rejection in stand-alone doublyfed induction generators with nonlinear loads," IEEE Transactions on Energy Conversion, vol. 31, no. 2, pp. 815-817, 2016.

[16] Y. Liu, W. Xu, F. Xiong, and F. Blaabjerg, "Harmonic voltage and current elimination of stand-alone brushless doubly-fed induction generator with nonlinear loads for ship shaft power generation applications," in Proceedings of the 2018 IEEE Energy Conversion Congress and Exposition (ECCE), pp. 7349-7355, Portland, OR, USA, September 2018.

[17] J. Poza, E. Oyarbide, D. Roye, and M. Rodriguez, "Unified reference frame dq model of the brushless doubly fed machine," IEE Proceedings - Electric Power Applications, vol. 153, no. 5, pp. 726-734, 2006.
[18] P. Rodriguez, A. Luna, I. Candela, R. Mujal, R. Teodorescu, and F. Blaabjerg, "Multiresonant frequency-locked loop for grid synchronization of power converters under distorted grid conditions," IEEE Transactions on Industrial Electronics, vol. 58, no. 1, pp. 127-138, 2011.

[19] V.-T. Phan and H.-H. Lee, "Improved predictive current control for unbalanced stand-alone doubly-fed induction generator-based wind power systems," IET Electric Power Applications, vol. 5, no. 3, pp. 275-287, 2011.

[20] S.-K. Chung, "Phase-locked loop for grid-connected threephase power conversion systems," IEE Proceedings - Electric Power Applications, vol. 147, no. 3, pp. 213-219, 2000.

[21] Y. Liu, W. Xu, T. Long, and F. Blaabjerg, "An improved rotor speed observer for standalone brushless doubly-fed induction generator under unbalanced and nonlinear loads," IEEE Transactions on Power Electronics, vol. 35, no. 1, pp. 775-788, 2020. 